\title{
THE AURORA SPACE LAUNCHER CONCEPT
}

\author{
Alexander Kopp $^{(1)}$, Sven Stappert ${ }^{(1)}$, David Mattsson ${ }^{(2)}$, Kurt Olofsson $^{(2)}$, Erik Marklund $^{(2,3)}$, \\ Guido Kurth $^{(4)}$, Erwin Mooij ${ }^{(5)}$, Evelyne Roorda ${ }^{(5)}$ \\ ${ }^{(1)}$ German Aerospace Center DLR, Institute of Space Systems, Space Launcher Systems Analysis, \\ Linzer Strasse 1, 28359 Bremen, Germany \\ alexander.kopp@dlr.de, sven.stappert@dlr.de
}

${ }^{(2)}$ Swerea SICOMP, Fibervägen 2, Öjebyn, SE-941 26, Piteå, Sweden david.mattsson@swerea.se, kurt.olofsson@swerea.se, erik.marklund@swerea.se

${ }^{(3)}$ Luleå University of Technology, Department of Engineering Sciences and Mathematics, SE-971 87, Luleå, Sweden

${ }^{(4)}$ Bayern Chemie GmbH, Liebigstr. 17, 84544 Aschau am Inn, Germany guido.kurth@mbda-systems.de

\author{
${ }^{(5)}$ Delft University of Technology, Faculty of Aerospace Engineering, Kluyverweg 1, 2629 HS, \\ Delft, The Netherlands \\ e.mooij@tudelft.nl, e.roorda@student.tudelft.nl
}

\begin{abstract}
This paper gives an overview about the Aurora reusable space launcher concept study that was initiated in late2015/early-2016. Within the Aurora study, several spaceplane-like vehicle configurations with different geometries, propulsion systems and mission profiles will be designed, investigated and evaluated with respect to their technical and economic feasibility. The first part of this paper will discuss the study logic and the current status of the Aurora studies, and introduces the first vehicle configurations and their system design status. As the identification of highly efficient structural designs is of particular interest for Aurora, the structural design and analysis approach will be discussed in higher level of detail.

A special design feature of the Aurora vehicle configurations is the utilization of the novel thin-ply composite material technology for structural mass reductions. Therefore, the second part of this paper will briefly discuss this technology, and investigate the application and potential mass savings on vehicle level within simplified structural analysis studies. The results indicate that significant mass savings could be possible.

Finally, an outlook on the next steps is provided.
\end{abstract}

\section{Keywords}

Launcher, hypersonics, reusable, spaceplane, thin-ply-composites

\section{INTRODUCTION}

It is well known that the high costs for space transportation have been and still are the limiting factor for large scale human exploration and exploitation of space. One of the main reasons for these high costs is the widely missing reusability of space launch vehicles. Additionally, the staging approach that requires the design, manufacturing and integration of several vehicles rather than just one vehicle, as well as limited flexibility, comparatively poor reliability and relatively high infrastructure costs of today's launch vehicles pose further cost drivers. Current activities on partly reusable space launchers aim on significant reduction of space transportation costs. Different approaches are envisaged, with the toss-back and vertical landing of the SpaceX Falcon 9 first stage surely being the most famous one. Other approaches include reusable winged fly-back boosters, or return and reusability of the most expensive launcher parts, such as the engines. Currently, it is not known which cost reductions can actually be reached with the proposed approaches. Although relative cost reductions in the order of, say, $10-30 \%$ are impressive, they are hardly sufficient to revolutionize space transportation. This would require cost savings of at least 
an order of magnitude. Order of magnitude cost savings in turn will however require new vehicle concepts. This logic made various aerospace companies and research institutions in the recent decades work on alternative launcher concepts, whereas many hopes were counting on the "holy grail" of space transportation, single stage to orbit vehicles (SSTO). As we know today, none of these activities has ever led to an operational system. Frequently, the technical hurdles turned out to be too high to be mastered with the available technology or the available budget. Either technological breakthroughs in propulsion technology or large scale vehicle mass reductions are required.

In the recent years technological advances have been achieved in many relevant areas. Most notably, with "thinply" composites a new material technology emerged that promises large weight reductions for launch vehicles (see Chapter 4). Other advances include for instance improved thermal protection systems [25], or rocket engines with increased thrust to weight ratios. Whether this is sufficient for enabling novel categories of space launch vehicles, is not known as of today, and needs to be investigated. With this idea in mind, the Aurora space launcher studies were initiated at DLR in late-2015/early-2016, quickly joint by Swerea SICOMP (S), Bayern Chemie (D), and Delft University of Technology (NL). Initial preparatory studies for possible configurations had been done in late 2015 at DLR, and indicated useful starting points for the Aurora studies [1]. The objective is to develop and analyze a series of spaceplane-type launch vehicles using thin-ply based carbon fiber reinforced plastic (CFRP) technology as well as the latest technological advances in other areas, and eventually to evaluate their technical and economic feasibility. Ideally, the result would be a technical feasible and fully reusable SSTO configuration able to provide large scale cost savings and flexibility increases with respect to state-of-the-art launch vehicles. However, this is a very ambitious aim, and experience from history advises to be cautious. Thus, deviations of the fully reusable SSTO approach may still be necessary. This may include launch assist systems, aircraft like drop tanks or small non-reusable upper stages. These approaches may lead to designs that could be designated as "semi-SSTO" or " 1.5 stage”. A similar approach was utilized for the innovative Hopper concept of the European FESTIP study [2]. The Hopper, shown in FIGURE 1, to some extent also serves as benchmark for certain Aurora configurations.

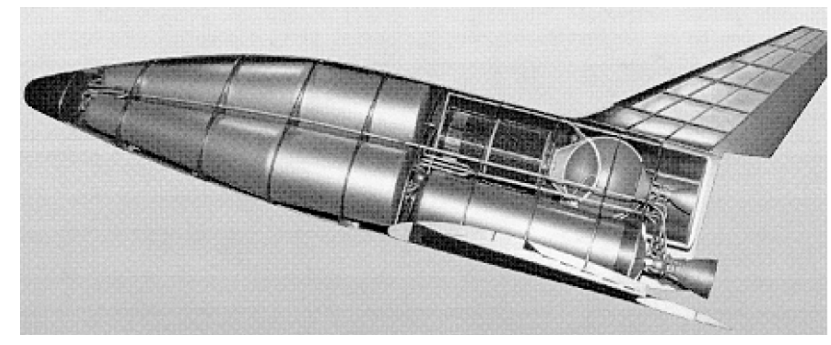

FIGURE 1. FESTIP Hopper concept [2]

\section{AURORA SYSTEM DESIGN OVERVIEW}

\subsection{Vehicle Design Rationales and Study Logic}

Design, assessment and comparison of different vehicle configurations will be based on a common vehicle and mission architecture. Preliminary assumptions and requirements include:

- Using FESTIP payload target requirements: $\geq 7 \mathrm{t}$ payload into $250 \mathrm{~km}$ low inclination Low Earth Orbit (LEO), $\geq 2 \mathrm{t}$ payload into $250 \mathrm{~km}$ high inclination LEO [2]; these target orbits are selected for configuration comparability reasons; reasonable target orbits for reusable launchers would most probably include higher altitudes and inclinations in the $45-90^{\circ}$ range

- Vehicle payload mass ratio of at least $1 \%$

- Horizontal Take-Off Horizontal Landing (HTOHL) preferred; Vertical Take-Off Horizontal Landing (VTOHL) may however be considered as well

- "Minimization of non-reusable equipment", "minimization of staging" (e. g. non-reusable upper stage as small as possible, if any)

Reusable launch vehicles may utilize different launch and landing methods, including the above mentioned HTOHL, Vertical Take-Off Vertical Landing (VTOVL) such as Falcon 9, or a combination in the form of VTOHL, as it is envisaged for many reusable booster concepts. The takeoff and landing approaches also dictate the vehicle configuration to a large extent. For instance, VTOVL configurations obviously do not require wings, which in turn is an essential feature of HTOHL and VTOHL configurations. Every approach has its advantages and disadvantages. The optimum approach will largely depend on the particular mission, the available technologies, operational issues, robustness and reliability considerations, and of course, costs. Main reasons for the HTOHL preference for Aurora include advantages on the operational and robustness side, which in turn may contribute to cost reductions and flexibility increases. Most notably, HTOHL configurations may at least in principle operate from any airfield, offer operation cost reductions due to aircraft-like operation, and may provide abort capability at any point of the mission.

SSTO compared to multi-stage vehicles is another tradeoff, whereas the principal drawback of SSTO is that it is just at, if not even still below, the edge of technical feasibility. Even if SSTO can be realized, payload mass fractions will always be lower when compared to multistage vehicles. The theoretical advantages on the other hand are impressive. Instead of several vehicles, only one vehicle has to be designed, manufactured, and operated. No stage integration, stage interfaces and stage separation procedures are required, thus reducing costs and failure 
probability. However, it remains open whether even with the application of the latest technologies SSTO with reasonable payload masses can already be realized. Therefore, as noted before, launch support systems, fighter-aircraft like drop tanks (expendable or reusable), or small upper stages are options to be considered for Aurora.

Within the previously discussed boundary conditions, large freedom exists concerning vehicle configuration design. Thereby, the optimum solution is far from being obvious. Fundamental trade-offs include the selection of the propulsion concept, whereas pure rocket configurations as well as combinations of rocket and airbreathing propelled vehicles will be investigated. This trade-off led to the creation of two branches within the Aurora studies, a pure rocket based branch (Aurora-R), and a combined air-breathing/rocket branch (Aurora-AB). Other trade-offs include the propellant selection, which is of course connected to the propulsion selection. Currently considered options include LOX/LH2 or LOX/kerosene combinations.

The first three vehicle configurations will represent three different vehicle design approaches: a LOX/LH2 rocketpropelled vehicle with large drop tanks, a LOX/kerosene flying wing rocket-propelled configuration, and an airbreathing configuration of not yet defined geometric configuration. The current design status of the three configurations will be discussed in Chapter 3 .

\section{AURORA CONFIGURATION DESIGN STATUS}

\subsection{Analysis Approach and Tools}

The first two Aurora configurations, R1 and R2, have been designed and investigated using common methods and tools. However, this does not have to be the case for future configurations (e.g. AB1), as different methods may be required for different types of vehicle configurations.

The design and analysis procedure for $\mathrm{R} 1$ and $\mathrm{R} 2$ can be summarized by:

- configuration- and simplified external and internal geometry-design based on required tank and payload bay volumina/dimensions;

- $\quad$ aerodynamic database (AEDB) generation:

o utilization of the simple program CAC which is based on handbook methods for the ascent trajectory (drag and lift);

o utilization of the inclination-methods based Hotsose code for hypersonic reentry (drag and lift, pressure and surface temperature distributions); o so far, no dedicated consideration of trimming;

- mass estimation using empirical/statistical methods;

- $\quad$ simplified upper stage design using structural indices or data from existing upper stages;

- $\quad$ simulation of ascent (main stage and upper stage) and reentry trajectory with the sophisticated trajectory optimization tool TOSCA;

- 1-dimensional thermal protection system (TPS) sizing (thickness and mass);

- $\quad$ structural analysis and optimization.

These steps have to be repeated on an iterative basis until a converged solution is found.

\subsection{Configuration Aurora-R1}

The first Aurora configuration R1 is not an actual vehicle proposal but rather an "experimental/trial" configuration that serves as a study vehicle for a first order estimation of thin ply-based mass savings and for identification of vehicle design sensitivities. Therefore, the focus was on designing a vehicle that provides representative boundary conditions, while no efforts were undertaken for any optimization. This will be left to future Aurora configuration designs.

The vehicle geometry is shown in FIGURE 2 and the basic geometry and mass characteristics are presented in TABLE 1. The vehicle is equipped with four large LOX and LH2 drop tanks, as well as with wing tip and aft mounted rocket engines of generic nature. The fuselage houses a payload bay of $10 \mathrm{~m}$ length, and another two non-integral LOX and 2 non-integral LH2 tanks. The drop tanks are pressure stabilized and do not have to carry any vehicle loads. The vehicle dry mass includes a $15 \%$ mass margin for structure, TPS and subsystems group, and 10\% for the propulsion group. Excluded from this margin policy are main fuselage and main wing structure, as their masses are computed via structural analysis with already high margins included. Take-off is assumed using a trolley-like system with a take-off velocity of $130 \mathrm{~m} / \mathrm{s}$. Conventional runway landing is assured using a retractable landing gear. The payload mass into a low inclination LEO transfer orbit of $80 \times 250 \mathrm{~km}$ is $7.8 \mathrm{t}$ when launching from an equatorial position in eastern direction. The corresponding payload mass fraction is $1.7 \%$, whereas the payload however requires a propulsion module for orbit circularization. Assuming a small propulsion module $(\mathrm{p} / \mathrm{m})$ with a generic specific impulse (Isp) of $350 \mathrm{~s}$, the payload in a $250 \mathrm{~km}$ circular orbit is approximately $7.5 \mathrm{t}$.

The current design is relatively inefficient with the fuselage propellant volume fraction being just 35\%, 
resulting in a largely oversized fuselage. Also, the drop tanks are large, resulting in high aerodynamic drag and cost penalties in case of non-reusability.
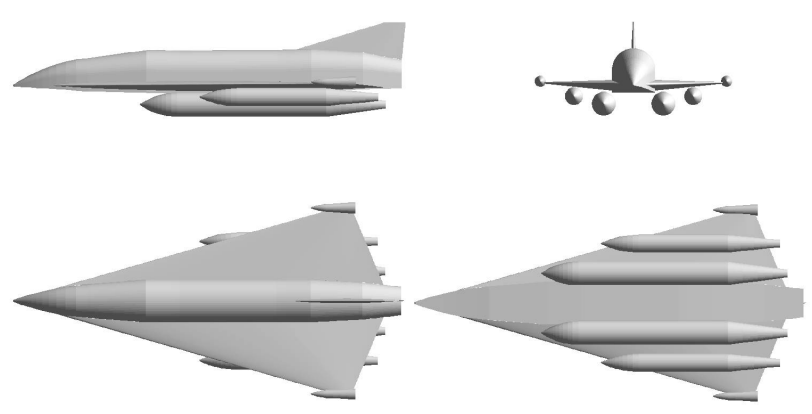

FIGURE 2. External geometry of experimental configuration Aurora-R1

\begin{tabular}{|l|r|}
\hline Length (excluding aft mounted engines) & $52.7 \mathrm{~m}$ \\
\hline Wing span (excluding wing tip engines) & $24.0 \mathrm{~m}$ \\
\hline Maximum fuselage diameter & $5.75 \mathrm{~m}$ \\
\hline Fuselage stored propellant mass & $150 \mathrm{t}$ \\
\hline Drop tank stored propellant mass & $240 \mathrm{t}$ \\
\hline Main stage dry mass* & $62.2 \mathrm{t}$ \\
\hline Payload mass (80 x 250 km transfer-orbit) & $7.8 \mathrm{t}$ \\
\hline Payload mass (250 x 250 km) using p/m & $7.5 \mathrm{t}$ \\
\hline Total take-off mass & $460.0 \mathrm{t}$ \\
\hline
\end{tabular}

*Including propellant residuals, reserves, RCS propellants, drop tanks

TABLE 1. Aurora-R1 main geometry and mass data

\subsubsection{Aerodynamic and Propulsion Models}

FIGURE 3 shows the lift/drag ratio $(L / D)$ for the ascent trajectory simulation computed with CAC, and FIGURE 4 shows the lift/drag ratios for reentry computed with Hotsose. Note the different axis scaling and Mach numbers $(M a)$. The ascent aerodynamic model includes the drop tanks. In the subsonic ascent flight, $L / D$ of up to 4.9 are reached. In transonic and supersonic flight the $L / D$ drops rapidly. The reentry AEDB does not consider the drop tanks in the model and shows maximum $L / D$ ratios close to 3 .

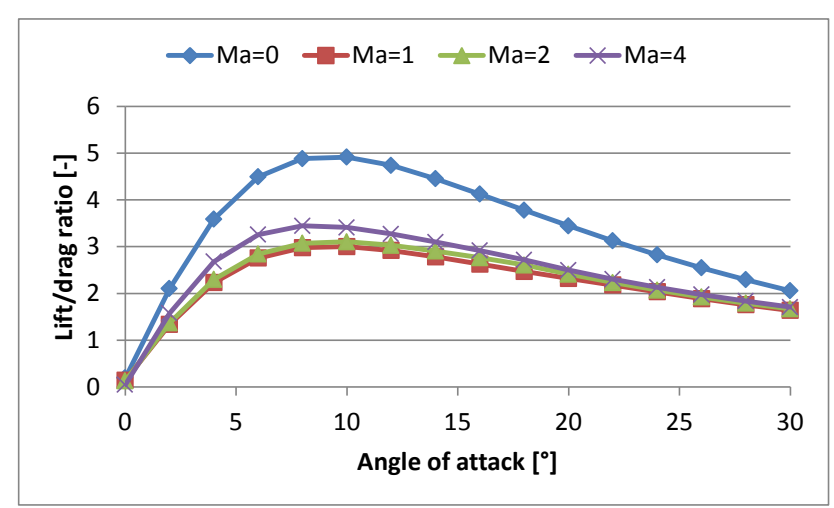

FIGURE 3. CAC computed lift/drag ratio for ascent (including drop tanks)

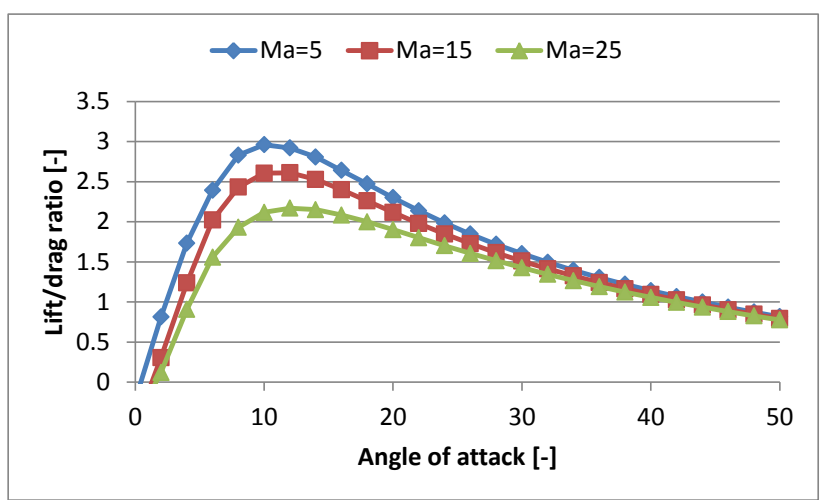

FIGURE 4. Hotsose computed lift/drag ratio for reentry (without drop tanks)

TABLE 2 lists the engine performance data, which are based on previous DLR-internal studies on LH2 rocket engines. The Isp are different for aft- and tip-mounted engines, as the tip-mounted engines are shut down earlier and thus nozzles which are better suited for lower altitudes are recommended. The mass flow of the tipmounted engines remains constant, while the aft-mounted engine will be throttled in the final ascent phase.

\begin{tabular}{|l|r|}
\hline Wing-tip engines Isp (sea level) & $389.0 \mathrm{~s}$ \\
\hline Wing-tip engines Isp (vacuum) & $438.5 \mathrm{~s}$ \\
\hline $\begin{array}{l}\text { Wing-tip engines mass flow (both engines } \\
\text { combined) }\end{array}$ & $475 \mathrm{~kg} / \mathrm{s}$ \\
\hline Aft-mounted engine(s) Isp (sea level) & $365.0 \mathrm{~s}$ \\
\hline Aft-mounted engine(s) Isp (vacuum) & $448.0 \mathrm{~s}$ \\
\hline $\begin{array}{l}\text { Aft-mounted engine(s) maximum mass } \\
\text { flow }\end{array}$ & $725 \mathrm{~kg} / \mathrm{s}$ \\
\hline
\end{tabular}

TABLE 2. Propulsion data

\subsubsection{Mission Profile}

FIGURE 5 shows selected ascent trajectory simulation data of the main stage. Drop tank ejection and wing-tipmounted engine shut-down occurs at $\mathrm{t}=200 \mathrm{~s}$ mission time. The maximum $\mathrm{n}_{\mathrm{z}}$ acceleration reaches $1.45 \mathrm{~g}$ shortly after take-off. The $\mathrm{n}_{\mathrm{x}}$ acceleration has been limited to $\mathrm{a}$ maximum of $4.7 \mathrm{~g}$ via engine throttling. At the end of the shown ascent simulation, payload separation occurs, and the payload circularizes its orbit using a propulsion module.

The main stage does not reach orbital velocity. TPS and structure shall however be designed such that SSTO operation is possible in principle. Thus, the reentry trajectory of the main stage (not shown) has been simulated assuming an orbital reentry. 


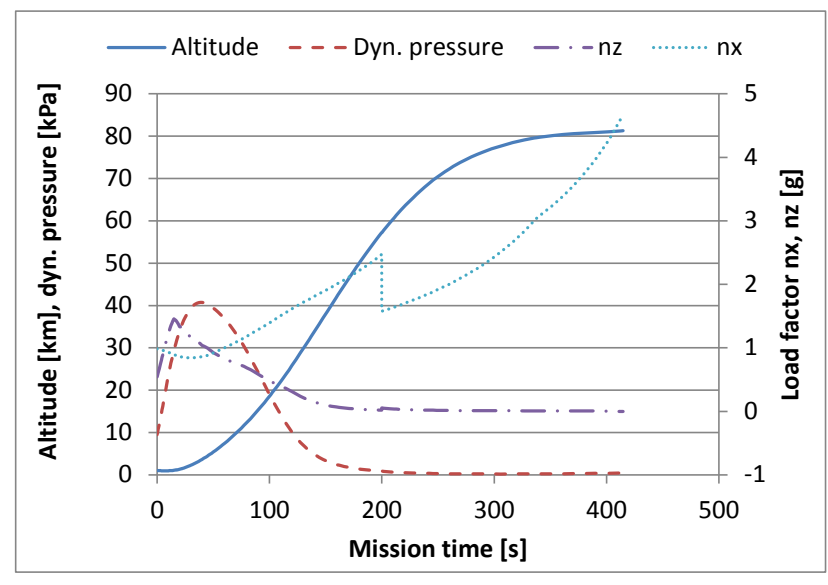

FIGURE 5. Ascent trajectory

\subsubsection{Airframe Design}

The structural analysis for Aurora-R1 has been done using a parametric ANSYS-based vehicle modelling and analysis tool named HySAP (Hypersonic vehicle Structural Analysis Program). HySAP iteratively adapts structural member thicknesses in an automated loop until convergence has been reached. A converged design is assumed as soon as the vehicle structural mass changes by not more than $1.5 \%$ in 4 successive iterations. The vehicle is completely modelled with shell elements and honeycomb sandwich design is utilized for all structural components. The ANSYS geometry model is shown in FIGURE 6.
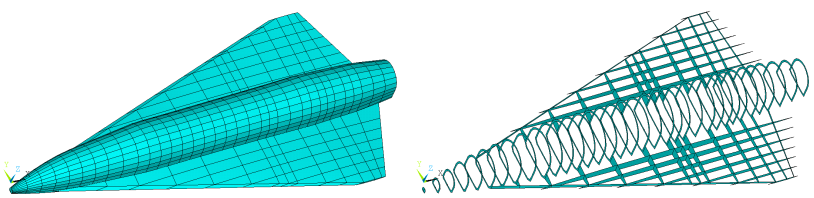

FIGURE 6. Aurora-R1 ANSYS geometry model; full model (left), skins removed (right)

Optimization of facesheet and core thicknesses is done iteratively on a local panel basis. Sizing of the facesheets includes Von Mises (metal) or Tsai-Wu (CFRP) for strength, as well as facesheet wrinkling, shear crimping, and intracellular buckling. The sandwich core heights are sized to prevent global buckling of the panels. Furthermore, the Shanley criterion according to [19] is applied for sizing of the fuselage frames against global buckling of the fuselage. CFRP facesheets are symmetric and balanced and consist of $0 \% 90 \% 45^{\circ} /-45^{\circ}$ plies with at least 2 plies per orientation, yielding a minimum of 8 plies per facesheet. Furthermore, a minimum thickness of $0.5 \mathrm{~mm}$ per facesheet has been considered for metallic and CFRP facesheets. The analysis is currently limited to 3 load cases (LC):

- LC1: Maximum $\mathrm{n}_{\mathrm{x}}$ during rocket ascent; an acceleration of $6.0 \mathrm{~g}$ is applied here, whereas the actual maximum acceleration in the current trajectory simulation is $4.7 \mathrm{~g}$
- LC2: $\mathrm{n}_{\mathrm{z}}=2.0$ g normal acceleration maneuver during ascent at hypersonic speed and with full tanks and flap deflection loads for trimming; this is conservative as the maximum normal acceleration found in the trajectory simulation is $1.45 \mathrm{~g}$; the pressure distribution was generated using an inclination based analysis code that also provides radiation-adiabatic equilibrium heat flux and temperature loads over the vehicle surface for thermal protection system (TPS) sizing

- LC3: Landing with main gear touch-down and a normal acceleration of $n_{z}=2.5 \mathrm{~g}$

The higher acceleration levels in LC1 and LC2 provide some contingency margins for covering dynamic effects and other secondary loadings that are not considered so far. Also, in LC2 so far only a hypersonic maneuver has been considered and hypersonic pressure distributions may not necessarily be as demanding as subsonic pressure distributions [20]. Future investigations will include more sophisticated loads analyses. Subsystems are modelled via mass point elements, while the propellant masses of the non-integral- and drop-tanks are introduced at the corresponding structural member positions.

A 1D TPS sizing code has been applied for computing the TPS masses for the complete vehicle surface. The required equilibrium surface temperatures and heat-flux distributions were computed by Hotsose along the complete trajectory, assuming turbulent boundary layers. For the current configuration no active cooling is required, with the maximum equilibrium temperature at nose and leading edges approaching $1700 \mathrm{~K}$. The vehicle surface is segmented into 12 temperature areas with an individual insulation thickness computed for each temperature area. Five different TPS material concepts are being used, including FRSI, AFRSI, TABI, AETB-TUFI, and CMC according to [21]. FIGURE 7 shows the maximum surface temperatures found along the reentry trajectory. An allowed structural temperature of $400 \mathrm{~K}$ was assumed in this analysis. For each temperature regime shown in the figure, the TPS was individually optimized. Non-colored (black) areas on the top side of the vehicle do not require a TPS as the temperatures remain below $400 \mathrm{~K}$ according to the heating analysis. This is a result of the reentry with high angles of attack during large fractions of the reentry trajectory. However, this remains to be confirmed by more sophisticated CFD analysis. 


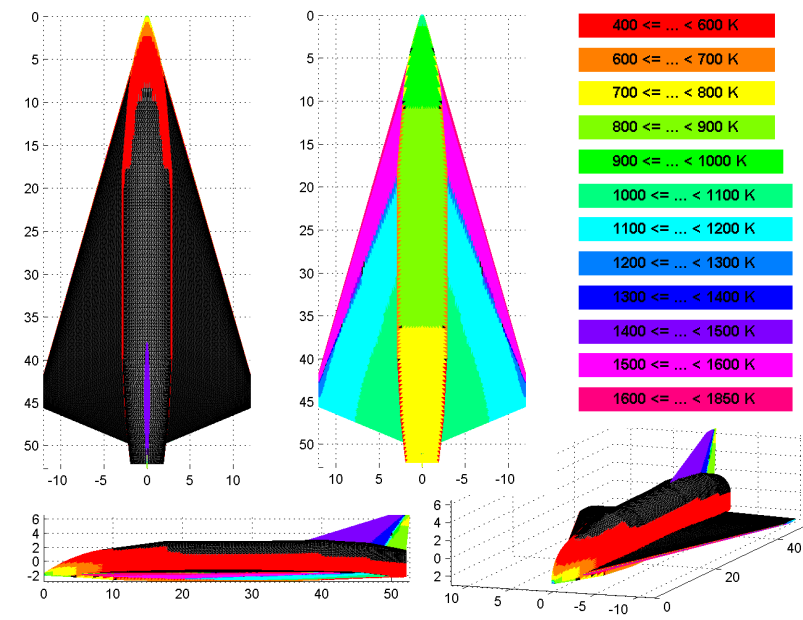

FIGURE 7. Maximum surface temperatures for TPS sizing; vehicle top side shown upper left, vehicle bottom side shown upper right

The insulation thicknesses are sized such that a userdefined maximum temperature $T_{\text {skin }}$ at the primary structure under the TPS is not exceeded. This maximum allowed structural temperature as assured by the TPS in turn will be applied to the wing and fuselage structure skins in the HySAP structural analysis. So far, no vehicle internal heat distribution analysis is available. Therefore, an assumption is made that the internal members ribs, spars and frames are at room temperature. This may present a worst case scenario as the temperature differences between the warm/hot skins and the cold internal members create strong thermal stresses.

A safety factor of 1.5 has been applied to all strength and buckling/stability allowables. For strength sizing of metallic structures, this applies to the yield rather than to the ultimate material strength. Furthermore, the computed structural masses will be increased by a non-optimum factor of 1.67 for the wings and 1.58 for the fuselage. This covers various structural details and unknowns that are not considered in the idealized "optimum" vehicle structural analysis, such as fasteners, bolts, attachments, local reinforcements, cut-outs, etc.

Vehicle structures made of 4 different materials have been considered: aluminum-lithium 2195 that had also been used for the Space Shuttle Super Lightweight Tank (SLWT) [22], and which is used here as a benchmark, titanium alloy Ti6Al4V in the heat-treated configuration, and two different CFRP composites. IM7/PETI-5 is a polyimide based high temperature composite with material data provided in [23]. Unfortunately, in the reference only a few data points are available and it is not yet clear whether the material properties provided already represent consolidated data. Nevertheless a hightemperature CFRP like the latter one is interesting for comparison. The second composite, IM7/APC-2, is a PEEK based material, with material data taken from [24]. For the composite materials an initial ply thickness of $t_{\text {ply }}=0.125 \mathrm{~mm}$ has been used. The structural skin temperature levels considered start at $T_{\text {skin }}=300 \mathrm{~K}$ with a step size of $25 \mathrm{~K}$. For IM7/APC-2, the maximum temperature considered is $394 \mathrm{~K}$, and $422 \mathrm{~K}$ for $\mathrm{Al}-\mathrm{Li}$. IM7/PETI-5 and titanium have been simulated up to $500 \mathrm{~K}$ and $600 \mathrm{~K}$, respectively. For comparative purposes always the whole vehicle structure is made of the particular material, although in practice of course different materials may be utilized for different structural components.

FIGURE 8 shows computed vehicle structural masses as well as the TPS mass as a function of structural skin temperature. Thereby, the structural masses as shown represent wing and fuselage mass, while other structural mass items such as non-integral tanks, fin or thrust-frame are considered in the mass budget as subsystems with empirical/statistical mass estimation. The aluminum and titanium vehicle structures feature a relatively strong mass increase with increasing temperature in particular due to thermal stress build-up. Titanium is not competitive which is largely a result of the high number of vehicle components that are sized by the $0.5 \mathrm{~mm}$ minimum thicknesses criterion, which in turn penalties high density materials. The CFRP composite structures instead show only small mass changes with increasing temperature. This is a result of the low CTE on the one hand, but also strongly results from the fact that a large number of panel facesheets are effectively "oversized" due to minimum ply number considerations (at least 8 plies per facesheet). If then the thermomechanical loads are increased, they can to a large extent be covered by the existing material without the need of increasing facesheet thickness. The striking structural mass increase for the IM7/PETI-5 structure beyond $450 \mathrm{~K}$ results from a relatively sharp degradation of material properties, in particular loss of compressive strength parallel to the fiber orientation as well as transverse tensile strength.

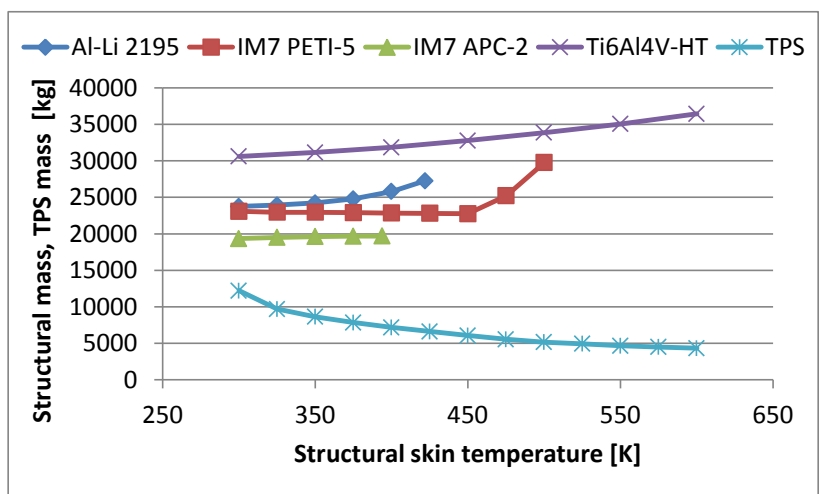

FIGURE 8. Structural masses and TPS masses for different allowed structural skin temperatures

The sum of structure and TPS mass is shown in FIGURE 9. The titanium and IM7/PETI-5 based vehicles feature an airframe mass minimum at $T_{\text {skin }}=450 \mathrm{~K}$. The mass minimum for 2195 is found at $T_{\text {skin }}=375 \mathrm{~K}$. The 
IM7/APC-2 based vehicle has its airframe mass minimum at the highest allowed temperature of $T_{\text {skin }}=394 \mathrm{~K}$. Based on these results, the mass saving potential of thin-ply composites will be investigated in Chapter 4 .

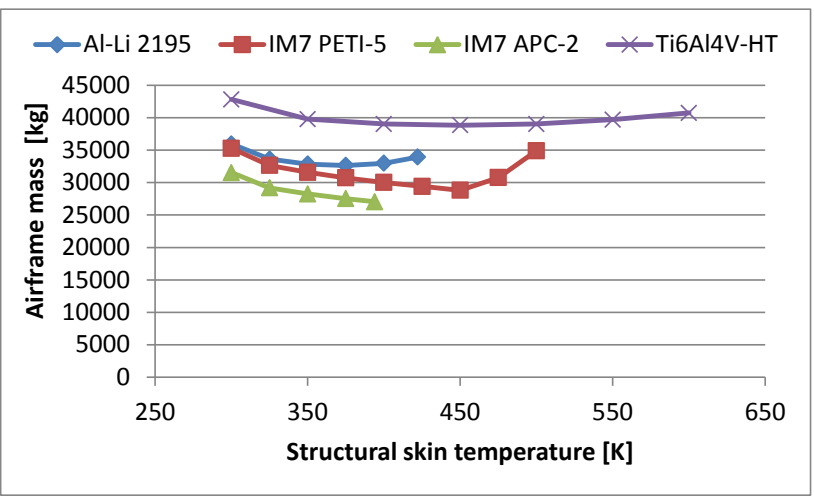

FIGURE 9. Airframe masses for different allowed structural skin temperatures

\subsection{Configuration Aurora-R2}

The very promising R2 configuration is currently under investigation and uses a LOX/kerosene propellant combination. The design focus of this configuration is on minimization of airframe mass and cost efficiency. Despite the lower specific impulse (Isp) of LOX/kerosene compared to LOX/LH2, LOX/kerosene offers several advantages that are particularly interesting for spaceplanelike launchers. Most notably, the high density of kerosene compared to LH2 allows for smaller and lighter propellant tanks. Nevertheless, LH2 fueled launchers typically achieve higher payload mass fractions due to the high energy density of LH2. In case of a winged launcher however the trade-off may shift in favor of kerosene, as kerosene can be stored in the otherwise empty wings just as it is done in conventional aircraft. This not only further reduces fuselage volume, but also reduces bending moments in the wings as the positioning of mass in the wings allows for better matching of inertia forces and lift forces. Consequently, extreme lightweight design can be realized. Also, the inherent rib/spar segmentation of the wings into compartments will eliminate the sloshing problem at least for the fuel, which otherwise could become a critical design issue for horizontal launchers. Furthermore, kerosene does not require cryo-insulations and on-ground cryogenic supply equipment. Considering that reusable cryo-insulations for LH2 temperatures are no state-of-the-art, and that the required work efforts for post-flight inspection, refurbishment and repair are hardly predictable at the time being, the rejection of LH2 in favor of kerosene could significantly improve operational readiness and cost performance of a launcher.

FIGURE 10 shows the preliminary vehicle geometry. The configuration resembles a flying wing design, but with a "bump" on the vehicle back. TABLE 3 provides the main geometry and mass data. In contrast to the previously described R1 configuration, the R2 configuration utilizes an expendable upper stage. Vehicle dry and payload mass depend on the particular launch configuration (see Section 3.3.3).
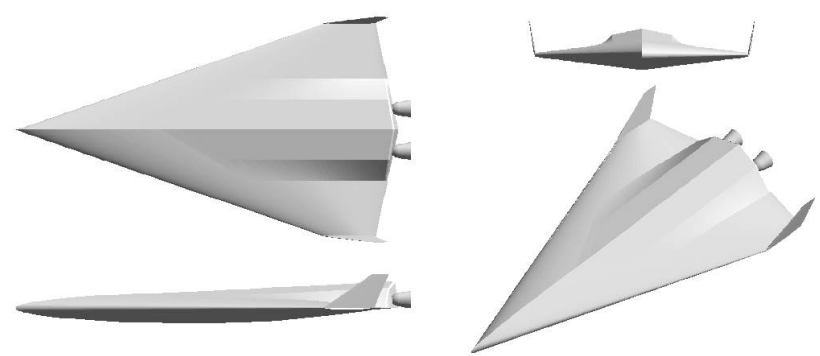

FIGURE 10. Preliminary geometry of Aurora-R2

\begin{tabular}{|l|r|}
\hline Length (excluding rocket engines) & $45.0 \mathrm{~m}$ \\
\hline Wing span & $25.0 \mathrm{~m}$ \\
\hline Maximum height & $3.9 \mathrm{~m}$ \\
\hline Propellant mass & $388 \mathrm{t}$ \\
\hline Main stage dry mass* & $47.6 \mathrm{t}$ \\
\hline Upper stage mass (without payload) & $8.0-9.4 \mathrm{t}$ \\
\hline Payload mass (250 x 250 km) & $7.0 / 7.6 \mathrm{t}$ \\
\hline Total take-off mass & $450.5 \mathrm{t}$ \\
\hline
\end{tabular}

*Including propellant residuals, reserves, RCS propellants

TABLE 3. Preliminary Aurora-R2 main geometry and mass data

The compact configuration with relatively high geometric moments of inertia, low moment arms, and efficient lift/inertia-force matching allows for large reductions of bending stresses. Together with thin-ply based CFRP primary structures, this enables an extremely lightweight airframe design. It is interesting to compare the vehicle mass characteristics with other LOX/kerosene (RP-1) propelled stages. Within the DLR internal META study a comparison of the structure index of historic or existing LOX/kerosene stages has been made [27]. The structure index is defined as stage dry mass without engines, fairings and interstages, divided by the total propellant mass including residuals, reserves and RCS propellants. In FIGURE 11 the structure index of Aurora-R2 is compared with the launcher stage structure indices found in the META study. Despite the lightweight design of Aurora, the structure index is significantly higher than it would be expected for conventional stages of comparable propellant mass. This is reasonable, as Aurora is a winged and reusable vehicle while all other stages are cylindrical rocket bodies and typically non-reusable. Note that the figure has been limited to propellant loadings of $450 \mathrm{t}$, while in the META study also heavier stages such as from Saturn V or N1 were considered. 


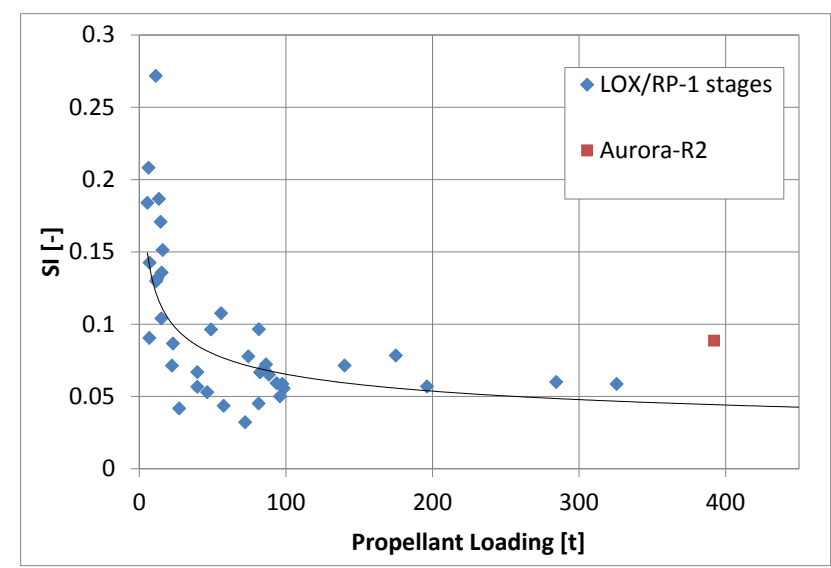

FIGURE 11. Comparison of Aurora-R2 structure index (SI) with other LOX/kerosene (RP-1) launcher stages as adopted from ref. [27]

\subsubsection{Propulsion, Propellant and Payload Accommodation}

FIGURE 12 shows possible internal arrangement and payload integration options. The LOX propellants will be stored in several parallel arranged cylindrical pressure vessels made of aluminum-lithium alloy. Kerosene is integrally stored in the outer wing sections. Operational issues concerning this approach are however still to be checked, in particular as the tanks cannot be pressurized for structural weight reasons. This would require a boostpump in order to provide sufficient pressure for the turbopumps. Also, unusable residual fuel masses need to be minimized.

The payload bay is situated between the LOX tanks. For the first vehicle design iteration, a center payload bay with bay doors on the vehicle upper side (similar to the Space Shuttle) is assumed. An alternative option would be an aft mounted payload bay, where the payload could be released "backwards" through a corresponding opening in the vehicle base plate between the engines. A similar solution was also considered for the FESTIP/Hopper concept [2]. Furthermore, payloads maybe suspended under the vehicle belly, similar to the R1 drop tank approach, and similar to the external store carriage of military aircraft. This would require fairing protection for the payloads, but would simplify the injection of multiple payloads into individual orbits. Also, existing upper stages (including fairings) of small launchers or sounding rockets could easily be used. Ideally, the vehicle would offer the opportunity of either internal or external payload accommodation, depending on the particular customer requirements. In case of external integration, additional propellant tanks may be stored in the payload bay area. The concrete positioning of tanks and payload bay is still to be defined, and will largely be driven by center of gravity (CoG) considerations. Thereby, multiple tanks and segmented kerosene wing tanks will allow for CoG control during ascent by sequential propellant tank depletion or fuel transfer. In a similar way the Concorde controlled its CoG position during flight [28]. On the other hand, multiple tanks and fuel supply lines will increase propellant system complexity and mass.

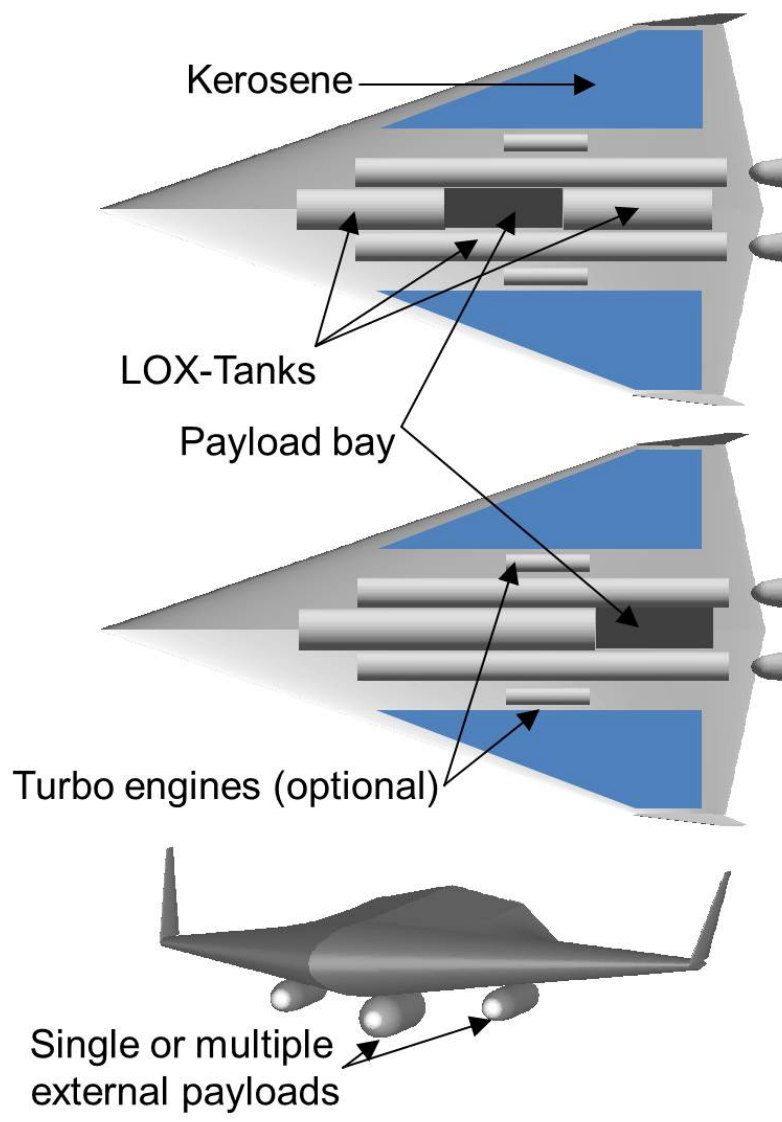

FIGURE 12. Preliminary internal arrangement and payload integration options (tank domes not shown)

Propulsive power is provided by two generic engines, with engine thrust to weight ratio and Isp derived from the Russian RD-193. At take-off, the vehicle thrust-to-weight ratio is 0.86, while conventional vertical take-off launchers require thrust-to-weight ratios significantly above 1. The utilization of two engines (or even just one) will largely reduce post-flight inspection/refurbishment efforts compared to multiple-engine RLV concepts such as the Falcon 9, where nine engines will have to be refurbished after every flight.

The vehicle is designed to maximize the operational readiness and flexibility. Therefore, sub-sonic return flights from a landing site to the launch site, as well as ferry flights, are considered to be realized by conventional turbo-engines. These engines can be integrally installed in the vehicle, which however reduces the payload performance and requires closable inlet and nozzle openings. Alternatively, the engines can be installed on demand at the landing site. In this case for instance underwing pylon installation would be possible. The drawback would be that always a set of engines as well as technicians and support equipment need to be available at 
the landing site. Currently, both approaches are investigated with using two turbo-engines, where engine mass and performance data are initially based on the Pratt \& Whitney F135-PW-100.

Note that fix installed turbo engines would also offer another fly-back possibility, as it would enable the vehicle to directly fly back to launch site after stage separation and "reentry" without requiring a separate landing site. The required fly-back kerosene mass however would have to be stored on board; thus significantly reducing payload performance and/or requiring a larger upper stage.

\subsubsection{Aerodynamic and Propulsion Models}

FIGURE 13 and FIGURE 14 show lift/drag ratios for ascent and reentry, respectively. The ascent lift/drag ratios achieve significantly higher values compared to R1, as the aerodynamic configuration is more efficient and no drop tanks are to be carried. In subsonic flight maximum $L / D$ ratios of up to 8 are reached. Remarkably, the $L / D$ at $M a=1$ are higher than the $L / D$ for $M a=2-4$. This has to be investigated in more detail using more sophisticated tools. The maximum reentry $L / D$ are also higher compared to R1 for $M a=5$. For $M a=15$ instead the maximum $L / D$ are comparable to R1. Note that the shown Mach numbers are 5, 10, and 15 (compared to 5, 15, 25 for R1), as the R2 maximum reentry Mach numbers are much lower than those of R1.

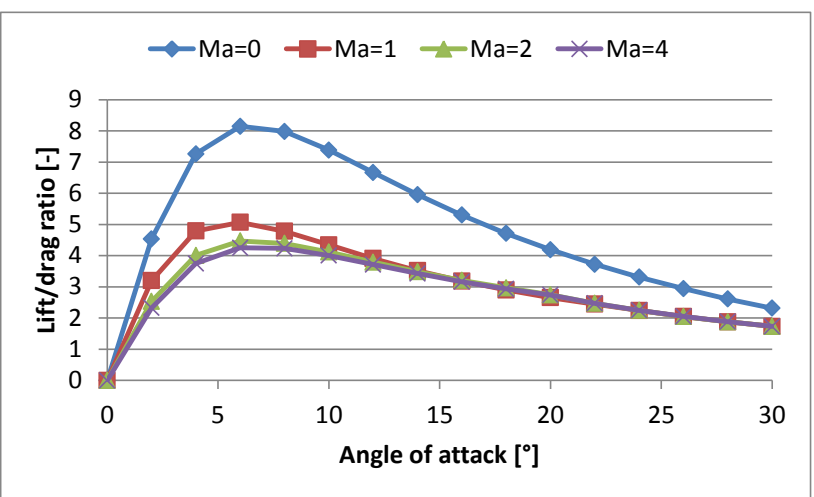

FIGURE 13. CAC computed lift/drag ratio for ascent

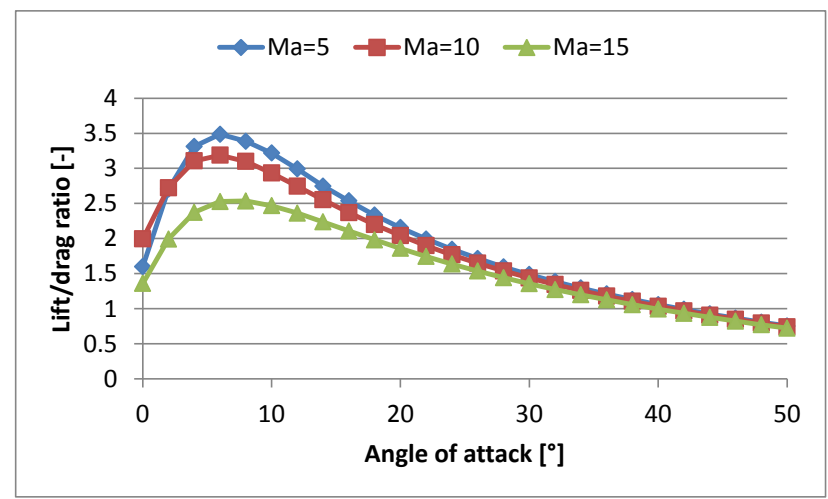

FIGURE 14. Hotsose computed lift/drag ratio for reentry
TABLE 4 lists the propulsion data for R2. The engines are still of generic nature, but as noted before closely based on literature data for the Russian RD-191/193 rocket engines and the Pratt \& Whitney F135-PW-100 turbofans in terms of performance, mass and geometry. For the turbo-engines, the thrust-specific fuel consumption (sfc) is shown rather than the Isp, as this is more common for turbo-engines. No sfc data were available for the F-135, thus the data shown in the table are assumptions based on data of comparable low bypass ratio turbofans. The turbo engines are only used for subsonic flight, and currently the sfc is assumed to be constant. In further analyses complete thrust/sfc databases as a function of altitude and Mach number will be set up.

\begin{tabular}{|l|r|}
\hline Rocket engines Isp (sea level) & $311.2 \mathrm{~s}$ \\
\hline Rocket engines Isp (vacuum) & $337.5 \mathrm{~s}$ \\
\hline $\begin{array}{l}\text { Rocket engines maximum mass flow } \\
\text { (both engines combined) }\end{array}$ & $1250 \mathrm{~kg} / \mathrm{s}$ \\
\hline Turbo-engine sfc (dry) & $22 \mathrm{~g} / \mathrm{KN} / \mathrm{s}$ \\
\hline Turbo-engine sfc (afterburner) & $38 \mathrm{KN} / \mathrm{s}$ \\
\hline $\begin{array}{l}\text { Turbo-engine maximum thrust (both } \\
\text { engines combined) }\end{array}$ \\
\hline
\end{tabular}

TABLE 4. Propulsion data

\subsubsection{Mission Profile}

Despite the compact character of the vehicle geometry, the internal volume is significantly larger than required for propellants, payload and subsystems integration. The reason is that the wing requires a certain minimum size in order to generate sufficient lift for take-off. Similar to the R1 configuration, a trolley-like launch support system is envisaged as baseline, but with a slightly higher take-off velocity of $140 \mathrm{~m} / \mathrm{s}$. The highly loaded wing together with high packing density results in a configuration that is very stable with respect to gusts and air turbulences. This is similar to low-level-flight optimized military strike aircraft. This is an important operational advantage when considering the frequent launch delays of conventional rocket launchers due to bad wind conditions. The retractable landing gear is also used for turbo-engine powered take-off in case of return flights from landing to launch site or for ferry flights. Thus, the gear is heavier than a pure landing gear would be, and is sized for a vehicle take-off mass of $100 \mathrm{t}$. Higher take-off velocities than with a trolley could be realized using rail-guided launch-support, similar to the FESTIP/Hopper approach [2]. In this case also the propellant loading could be increased as with higher take-off velocities more aerodynamic lift is generated. By that even a quasi-SSTO approach could be possible with small payloads. The drawbacks however include higher infrastructure costs and reduced operational flexibility (launch site \& azimuth). A third option is the utilization of a take-off gear for supporting the complete $450 \mathrm{t}$ take-off mass. This would reduce the take-off velocity and significantly increase vehicle dry mass due to the heavy gears, but on the other hand would provide maximum operational 
flexibility and minimum infrastructure costs. As every launch method offers individual advantages and disadvantages, the vehicle design will incorporate the principal possibility of applying all three launch methods. This shall be realized by defining common interfaces that can be used to mount the vehicle either on a trolley, or on a rail-launch system. Furthermore, gear bays and support structures are to be designed such that the lightweight landing gear can be replaced by a heavier take-off gear if demanded. This three-fold approach offers the advantage that vehicle operators could decide by themselves which launch method and corresponding facilities they want to realize. Moreover, this eliminates some critical development paths in the vehicle development.

The baseline mission transports a $7 \mathrm{t}$ payload from Kourou into a low inclination $250 \mathrm{~km}$ LEO. Other target orbits have also been simulated, including ascents for vehicle configurations with fix-installed or removable turbo-engines. TABLE 5 lists the payload (p/l) performance for selected example orbits including upper stage $(\mathrm{u} / \mathrm{s})$ mass and stage separation velocity $\mathrm{v}_{\text {sep }}$ (relative/inertial). A configuration with removable turbo engines (and without corresponding mass budget for inlet and nozzle support structures) would allow for a $9 \%$ higher payload mass into the baseline orbit.

\begin{tabular}{|c|c|c|c|c|}
\hline Orbit & $\begin{array}{l}\text { Turbo- } \\
\text { engines }\end{array}$ & $\mathbf{u} / \mathbf{s}$ mass & $\mathrm{p} / \mathbf{l}$ mass & $\begin{array}{c}\mathbf{v}_{\text {sep }} \\
\text { rel./inert. }\end{array}$ \\
\hline $\begin{array}{l}250 \mathrm{~km} \\
\text { equatorial }\end{array}$ & Fix & $8.0 \mathrm{t}$ & $7.0 \mathrm{t}$ & $5.4 / 5.9 \mathrm{~km} / \mathrm{s}$ \\
\hline $\begin{array}{ll}250 & \mathrm{~km} \\
\text { polar } & \\
\end{array}$ & Fix & $9.4 \mathrm{t}$ & $5.6 \mathrm{t}$ & $5.3 / 5.3 \mathrm{~km} / \mathrm{s}$ \\
\hline $\begin{array}{l}250 \mathrm{~km} \\
\text { equatorial }\end{array}$ & Rem. & $7.4 \mathrm{t}$ & $7.6 \mathrm{t}$ & $5.6 / 6.1 \mathrm{~km} / \mathrm{s}$ \\
\hline $\begin{array}{l}450 \mathrm{~km} \\
\text { equatorial }\end{array}$ & Rem. & $7.8 \mathrm{t}$ & $7.2 \mathrm{t}$ & $5.6 / 6.1 \mathrm{~km} / \mathrm{s}$ \\
\hline
\end{tabular}

TABLE 5. Payload performance and upper stage separation velocity for different missions

The high separation velocity together with the comparatively high $L / D$ ratio allows for reaching the landing site of Ascension Island in the Atlantic Ocean. Also the coastal regions of the African main land can be reached. FIGURE 15 displays the current baseline trajectory with the Ascension Island landing site.

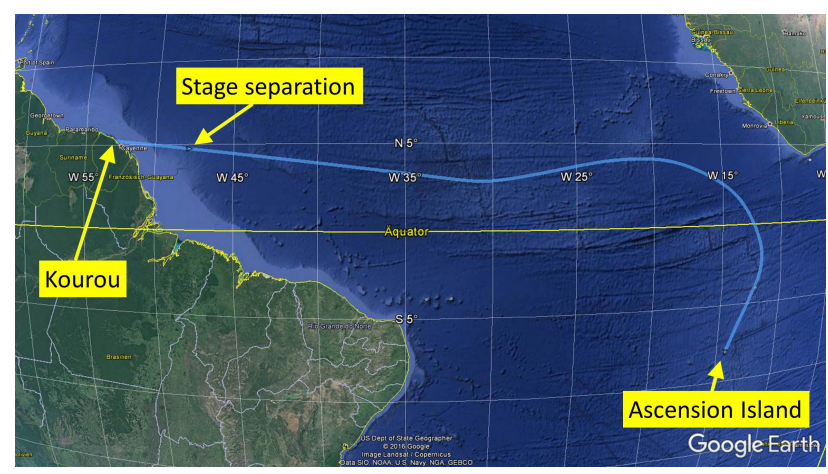

FIGURE 15. Preliminary baseline trajectory displayed with Google Earth
FIGURE 16 shows altitude, dynamic pressure, as well as $\mathrm{n}_{\mathrm{x}}$ and $\mathrm{n}_{\mathrm{z}}$ load factor profiles along the baseline trajectory. The steep descent after reaching apogee at $150 \mathrm{~km}$ altitude yields a relatively strong mechanical and thermal (not shown) load peak around $700 \mathrm{~s}$ mission time.

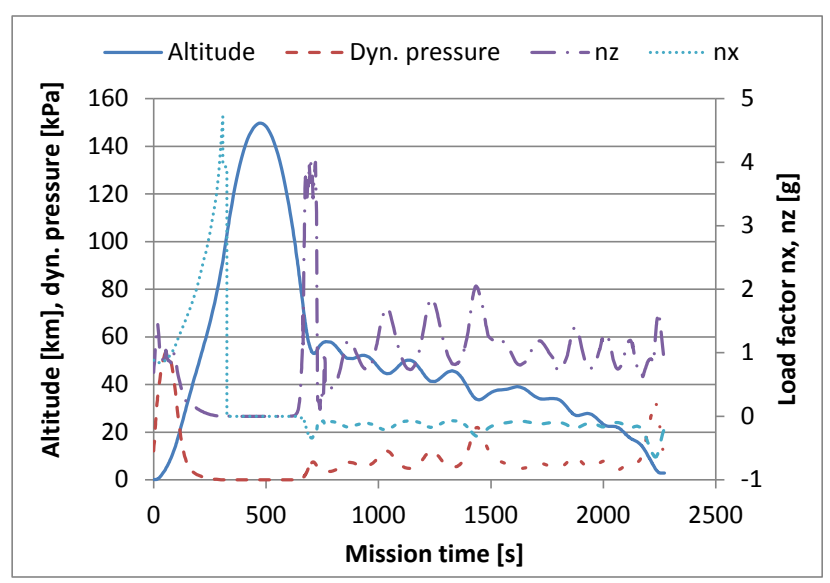

FIGURE 16. Preliminary baseline trajectory profile

Next to trolley-launch configurations, also a preliminary rail-launched configuration was investigated. In this case a take-off velocity of $170 \mathrm{~m} / \mathrm{s}$ was assumed (for Hopper $160-180 \mathrm{~m} / \mathrm{s}$ were considered [2]). The propellant loading was increased by $25 \%$, the rocket engine thrust by $20 \%$, and no turbo-engines were considered in the mass budget. With that, the vehicle can reach LEO without further staging. However, in this case the achievable payload mass is negligible small. Nevertheless such a configuration could be of interest as it offers the possibility to transport payloads or personal from orbit back to Earth. Also on-orbit servicing missions could be accomplished, given that the mass of the servicing equipment is small.

\subsubsection{Airframe Design}

Similar to R1, the R2 configuration utilizes a CFRP sandwich primary structure. As noted before, in the outboard wing section the primary structure simultaneously forms the kerosene integral tanks. A similar design with (metallic) honeycomb sandwich integral tanks was, for instance, already utilized in the 1960s for the XB-70 bomber [26].

The boundary conditions and load cases for structural design are similar to those of the R1 configuration. Also the maximum accelerations in the trajectory simulation are in the same order. However, with $n_{z}=3.8 \mathrm{~g}$ the reentry load factors are significantly higher than for R1. Thus, the reentry load case has been added to the structural analysis. Based on the results of the R1 configuration, only CFRP structures will be considered, where the utilization of thinply composites is envisaged. This will be discussed in Chapter 4.

The TPS analysis was conducted in a similar manner as 
for R1 and yields a 30\% lower TPS mass compared to R1, as separation velocity and vehicle surface area are lower. In fact, the majority of the vehicle upper side would not require a TPS according to the aerothermodynamic heating analysis, similar to R1. However, at least a coating would potentially be required to protect the CFRP structure from the environmental conditions. Furthermore it is to be mentioned that the inclination based heating analysis is not able to consider all potentially relevant flow phenomena, thus introducing some uncertainties in the TPS analysis.

Further TPS analysis will place a stronger focus on robustness/maintenance considerations. Currently, the TPS analyses of Aurora R1 and R2 are based on Space Shuttle materials. The reusable Space Shuttle used an intricate net of ceramic TPS tiles, which could withstand very high temperatures, but were very fragile and many tiles needed to be replaced after flight, leading to very high maintenance cost. For an RLV, apart from fulfilling the thermal requirements, the main requirements would be related to reusability and reliability. Lessons learned from the Space Shuttle imply that the TPS has to be more robust and less sensitive to damage, which would exclude the ceramic tiles. NASA concluded that thermal protection tiles with a metallic outer protecting casing would be very promising and this new technology was applied in the conceptual design of the X-33 [3]. Based on these considerations, further Aurora TPS sizing studies will be focused on metallic TPS systems.

\subsection{Aurora-AB1 Design Perspectives}

Different propulsion options are available for the airbreathing branch of Aurora, whereas combined cycle engines that integrate different propulsion types in one engine are considered in order to save mass and reduce engine dimensions. Such combined cycle engines may be grouped into turbine based combined cycles (TBCC) or rocket based combined cycles (RBCC).

For the first air-breathing configuration AB1 a TBCC cycle will be investigated. This option will consist of two main components: a turbojet needed to accelerate the vehicle up to a flight Mach number of approximately 2.1 and a Ramjet engine which will take over afterwards and cover the flight trajectory up to a flight Mach number of $5(+)$. For higher Mach numbers the air-breathing mode has to be shut down and a rocket motor has to take over. For Aurora-AB1 no vehicle design is available so far, as it is expected that engine geometry, integration and flow path requirements will largely define the vehicle geometry. Thus, this sub-section will focus on the discussion of the propulsion system rather than on the vehicle design itself.

A preliminary sketch of the TBCC based propulsion system for AB-1 is shown in FIGURE 17. To keep the required space as compact as possible for this configuration an "in-line" arrangement has been chosen which requires a single air flow path per engine. For the sake of modularity, each engine should be placed in an individual compartment which houses a separate variable geometry air intake with isolator duct, the turbojet engine, the after burner or Ramjet, and an adjustable thrust nozzle. Critical to the overall engine design are the air intakes since they have to provide a high total pressure recovery in combination with low drag especially during the transonic regime. Further, at high flight Mach numbers the physical stability of the air intake also becomes more important. For this purpose, two-dimensional air intakes have been chosen instead of axisymmetric ones. While an axisymmetric air intake has the advantage of a light weight design in combination with no or only minor sealing problems, it must be doubted that it can provide the required performance (total pressure recovery, drag, stability) along the complete flight path. Especially since its only measure to adapt to the actual flight conditions is to shift a central compression cone backward and forth in order to adjust the oblique compression wave pattern to the flight Mach number.

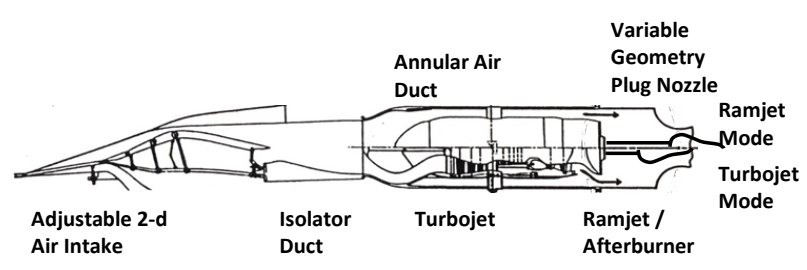

FIGURE 17. Sketch of TBCC engine for Aurora-AB1

A two dimensional air intake with variable ramps can compensate some of the shortcomings of an axisymmetric cone since it consists of two to three compression ramps of which each one's slope could be varied individually according to the actual flight state. Drawbacks however include higher actuator masses and sealing issues between ramps and side walls. The turbojet will be surrounded by an annular air duct which will act as a bypass system during the turbojet operational regime. With increasing flight Mach number, first an afterburner will be ignited operating concurrently with the turbojet. With transition to pure Ramjet operation, the turbojet will be shrouded by a covering system and the total amount of captured air will be led through the annular air duct into the Ramjet combustion chamber. In order to extract maximum thrust generation from the Ramjet, a nozzle with a variable throat is envisaged. Here, a so called plug or pintle nozzle will be employed that is able to vary the nozzle throat by axial shifting. Bayern Chemie has tested this technology successfully in 2015 for combustion chamber conditions almost identical to the ones relevant here.

In contrast to the wing mounted engine installation approach of SABRE/SKYLON [4], for the AB1 version of Aurora the engine compartments will probably be located on the dorsal or leeward side of the wings, leading to a highly integrated vehicle/propulsion sub system configuration. This choice has been made for limiting lift 
generation that could otherwise become unnecessary high, associated trimming considerations, as well as volumetric/integration considerations. In fact, this unconventional arrangement might bear some advantages over the common approach. But this has to be investigated more meticulous and in detail in a forthcoming system study.

A second variant of a possible air-breathing combined cycle engine could be seen as a derivative or modification of the SABRE concept of Reaction Engines [4]. Here, the rocket part of the SABRE is used such that a part of the air captured by the air intake is diverted into the heat exchanger/compressor/rocket motor cycle of the SABRE while the main part of the captured air is led through the main duct. During the first trajectory phase, the engine acts as an ejector rocket. After having reached a sufficiently high flight Mach number, the rocket motor is shut down and the engine operates in pure Ramjet mode. This RBCC-concept could be an option for an Aurora AB2 configuration, with a preliminary sketch being shown in FIGURE 18.

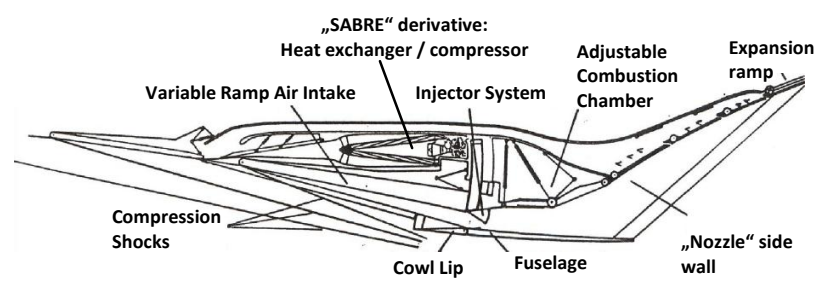

FIGURE 18. Sketch of potential RBCC engine

The TPS of A rocket based Aurora configuration is dimensioned by the re-entry loads. An Aurora-type RLV with air-breathing propulsion however will experience high thermal loading both during ascent and descent. Critical areas are the nose region, wing leading edges, (air-breathing) engine inlets, and control surfaces, to name a few, since nose and leading edge radii have to be small in order to provide low aerodynamic drag. However, when the surface area is small, e.g., a small nose or a leading edge, one is faced with two problems: the surface area to radiate heat is too small to matter, and the heat load is extremely high, as it is inversely proportional with the radius. Alternative solutions can be found in semi-passive and active TPS, of which an overview is presented in FIGURE 19. The fundamental operating principle is to use a coolant that transports the heat.

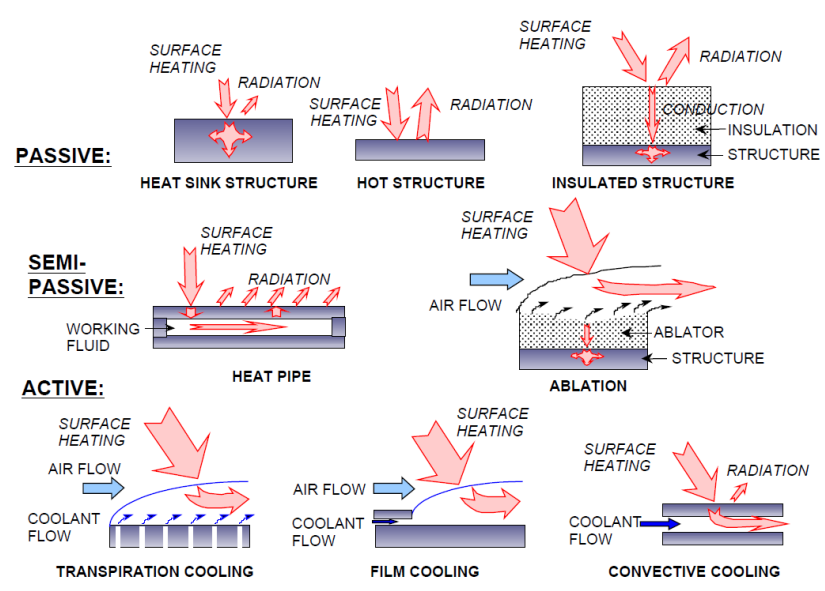

FIGURE 19. Types of thermal protection systems [5]

\subsection{Concept Comparison}

TABLE 6 provides a comparison of the R1 and R2 configuration. For AB1 no mass data are available yet. It is interesting that both configurations, despite using different propellants, achieve similar payload masses with similar take-off masses. From conventional launcher design experience, higher payload masses would be expected for a LH2 launcher compared to a kerosene launcher of similar take-off mass. However, firstly the R2 configuration features a more efficient system integration. Secondly, the staging Mach number is lower for the R2 main stage, while R1 achieves almost orbital velocity. This is a performance drawback for R1, as the complete main stage mass has to be accelerated to this high velocity.

From an operational \& cost perspective the R2 configuration is superior, as kerosene technology can be expected to feature lower maintenance and operation costs compared to cryogenic LH2 technology. Moreover, the large drop tanks of R1, if non-reusable, obviously form a large cost penalty. The R2 configuration further benefits from turbo engine utilization and high subsonic $L / D$ ratios, which improves vehicle flexibility and autonomy with respect to launch and landing site selections and ferry flights.

\begin{tabular}{|c|c|c|}
\hline & R1 & R2 \\
\hline Length & $52.7 \mathrm{~m}$ & $45.0 \mathrm{~m}$ \\
\hline Wing span & $24.0 \mathrm{~m}$ & $25.0 \mathrm{~m}$ \\
\hline Propellant mass & $390 \mathrm{t}$ & $388 \mathrm{t}$ \\
\hline Main stage dry mass* & $62.2 \mathrm{t}$ & $47.6 \mathrm{t}$ \\
\hline $\mathrm{U} / \mathrm{s}$ or $\mathrm{p} / \mathrm{m}$ mass & $0.3 \mathrm{t}$ & $8.0-9.4 \mathrm{t}$ \\
\hline Payload mass** & $7.5 \mathrm{t}$ & $7.0 / 7.6 \mathrm{t}$ \\
\hline Total take-off mass & $460.0 \mathrm{t}$ & $450.5 \mathrm{t}$ \\
\hline
\end{tabular}

TABLE 6. Comparison of R1 and R2 configuration 


\section{THIN PLY COMPOSITES FOR AURORA}

Thin-ply composites are of special interest for the Aurora study, as this technology promises significant structural mass savings for launch vehicles. Therefore, this Chapter will provide a brief overview of the thin-ply technology and associated research results. Afterwards, the application of thin-ply composites for the R1 and R2 configuration will be discussed.

\subsection{Thin-Ply CFRP Technology - Overview}

The achievable linear elastic strain level, when the material is essentially undamaged, is an important material characteristic for the dimensioning of many composite material structures. The first significant damage is commonly the development of matrix micro-cracks, eventually leading to a fully developed matrix crack running parallel to fibers over the width of the ply. There are several ways to increase the onset level of matrix cracking, typically using altered or added material constituents. Several drawbacks might however occur like the need for specialized material combinations, lowered fiber content, lowered glass transition temperature Tg, complex interactions between constituents, complicated manufacturing, quality control during and after manufacturing, cost, etc. Another approach is to instead change the local fiber architecture to thin-ply laminae, while keeping the material constituents unaltered as seen in FIGURE 20.

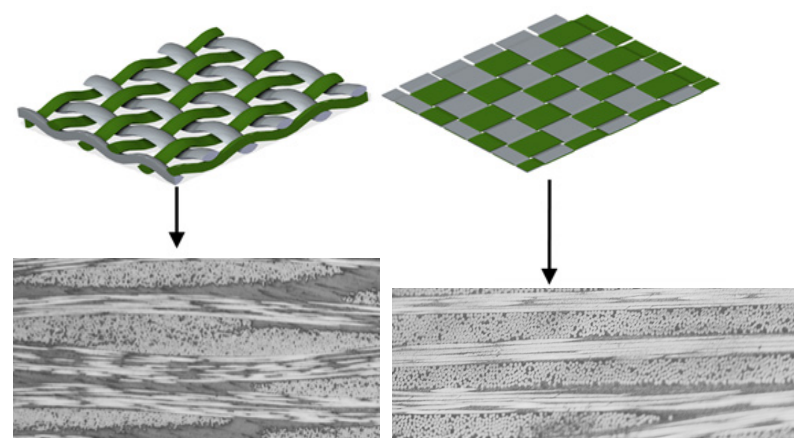

FIGURE 20. Conventional plain weave fabric (left) compared to a thin spread tow woven fabric (right)

The in-plane transverse strength $Y$ or shear strength $S$ of an unconstrained unidirectional (UD) composite material may be measured directly, but is also via fracture mechanics linked to the intrinsic defect size and material fracture toughness. It is noted that $Y$ increases for small volumes as the occurrence and size of defects decreases, as explained by the Weibull statistical strength theory. It is also noted that the strengths depend on the thickness of the ply, its position in the laminate and on the neighboring plies. The conditions for the propagation of matrix cracks are much more favorable for the case of a UD composite than for a thin ply in a multi-axial laminate. Energy considerations show that a small matrix crack will first grow in the ply thickness direction. Once the matrix crack has reached the full thickness of the ply it will grow along the fibers, and its propagation being controlled by fracture mechanics. The thickness of the ply and the influence of neighboring plies change the boundary conditions for the crack growth. Therefore, the strength (i.e. in-situ strength) associated with a matrix dominated failure of a ply in a composite laminate is not a material property but rather a structural one, as illustrated according to the schematic picture in FIGURE 21.

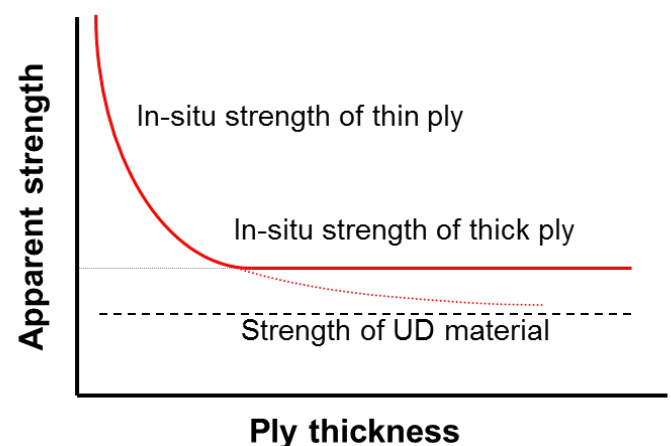

FIGURE 21. General effect for apparent mechanical strength $(Y$ or $S$ ) versus ply thickness

The effect of reduced ply thickness for carbon/epoxy specimens with $0^{\circ} / 90^{\circ}$ lay-up tension tested at $-50^{\circ} \mathrm{C}$ can be seen in FIGURE 22. The ply thickness is $300 \mu \mathrm{m}$ for pre-preg, L3 is $150 \mu \mathrm{m}, \mathrm{L} 2$ is $100 \mu \mathrm{m}$ and L1 is $50 \mu \mathrm{m}$. Thicknesses $<100 \mu \mathrm{m}$ commonly give significant improvements by delaying the onset of matrix cracking. The fully developed crack in a thin-ply material is furthermore geometrically much smaller than for traditional roving laminae.

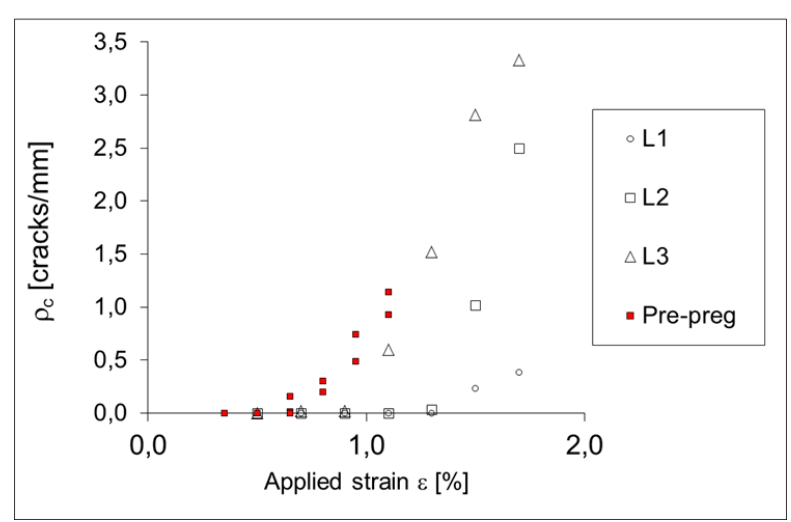

FIGURE 22. Crack density vs applied tensional strain at $-50^{\circ} \mathrm{C}$ for $0^{\circ} / 90^{\circ}$ lay-up

The Swedish Oxeon company pioneered the spread tow thin-ply carbon fiber material in 2003 [6]. Several other material suppliers have in recent years introduced similar material types. The first applications were mainly sporting goods, car parts, boats, light aircraft etc. The use has however spread to advanced applications like aircraft and space, where Solar Impulse 2 (first solar driven round-theworld flight) is an example from the aircraft industry [7]. 
It is likely that some of these new applications could not have been realized using traditional composite materials. Thin-ply composites commonly enable weight savings of $10-30 \%$ compared to a traditional roving based material with identical material constituents, depending on the specification for the studied structure. A prime example for space applications is recent work by NASA where a $5.5 \mathrm{~m}$ diameter cryogenic demonstrator test tank was developed in cooperation with the Boeing Company. This liner-less tank is using thin-plies for permeation barrier, ventable and purgeable sandwich structures, and structural health monitoring to support damage tolerance [8]. The tank passed a series of fill-and-drain tests, containing cryogenic liquid hydrogen with acceptable seepage. Weight savings over aluminum tanks approached the 35\% target set by NASA. NASA describes extended thin-ply composites applications like this in their recent development call "Game changing development program, thin-ply composites for space exploration applications" [9]. According to this, thin-ply composites are those with cured ply thicknesses ranging from $64 \mu \mathrm{m}$ to $25 \mu \mathrm{m}$ or less. Their potential is described as: "Thin-ply composites hold the potential for reducing structural mass and increasing performance due to their unique structural characteristics”. This may include [9], [10]:

- Improved damage tolerance,

- Resistance to micro-cracking (including cryogenic-effects),

- Improved aging and fatigue resistance,

- $\quad$ Reduced minimum laminate thickness,

- Increased scalability,

- Increased bearing strength.

\subsection{Results of the CHATT Project}

Thin-ply materials have shown radical improvements in critical material properties during use in the recent EU project CHATT (Cryogenic Hypersonic Advanced Tank Technologies) [11], [12]. On coupon specimen level, tensile tests of TeXtreme ${ }^{\circledR}$ thin-ply laminates have been performed at $-50^{\circ} \mathrm{C}$ and $-150^{\circ} \mathrm{C}$ and the evolution of damage has been analyzed. Very high strain levels of $1.7 \%$ have been applied to the test samples and the obtained results proved that formation of micro-cracks is significantly delayed in the thinnest plies. Thermal fatigue tests of TeXtreme ${ }^{\circledR}$ thin-ply laminates were performed to study the micro-cracking in samples representing a linerless tank concept subjected to a high number of thermal loading cycles. The results showed only a few microcracks in the thickest plies after 100 cycles and no microcracks were found in the thinnest ones (50-100 $\mu \mathrm{m})$. These results show a promising application of thin plies as a gas barrier in liner-less tanks.

The hybrid laminate concept that was chosen for the final subscale demonstrator tube contains both traditional roving- and thin-ply materials in the laminate. In this case, the traditional roving plies will fail due to thermal and mechanical loads during service life whereas the thin plies are effectively damage free (assuming a crack in the adjacent roving ply does not progress through the thin plies). The final subscale demonstrator tube is $2 \mathrm{~mm}$ thick and has 3 integrated TeXtreme ${ }^{\circledR}$ thin plies. The function is hence similar to having 3 compliant (similar material properties as the roving laminae) load carrying liners in the structure, with predicted benefits regarding progressive damage distribution needed to achieve a leakage path through the tank wall, resulting in leakage redundancy for large tank structures. The selected liner concept is hence potentially superior to the use of one non-load carrying liner (polymeric or metallic) with its sensitivity to defects for large tanks and differing coefficient of thermal expansion (CTE). Manufacturing methods suitable for liquid composite manufacture (wet filament winding, resin transfer molding RTM) of both thin-ply laminates and hybrid laminates, that can be scaled to larger structures, were developed in the project. The manufacturing challenge has been to achieve high quality and reduced cycle times. Processing issues have been solved using a combination of process simulation and manufacturing equipment modifications. The manufactured demonstrator tubes can be considered as having reasonably good quality. The manufactured subscale demonstrator tubes have successfully been tested in CHATT towards the demanding loading conditions specified in the project, indicating that the TeXtreme ${ }^{\circledR}$ material performs well as a load carrying liner material. The results from the testing showed that the selected winding angle of $\pm 25^{\circ}$ for the plies effectively stopped the micro-cracks from growing through the thickness of the demonstrator. Hence, no leakage path was obtained through the laminate during testing although the axial tension load reached close to $1000 \mathrm{kN}$, corresponding to $1.6 \%$ applied axial strain, combined with $-150^{\circ} \mathrm{C}$ and an inner pressure of 3 bar. Pointwise fractography evaluations after testing showed that the void content in the critical thin ply layers is $<0.5 \%$ while the void content in the roving plies is 3\%, see FIGURE 23.

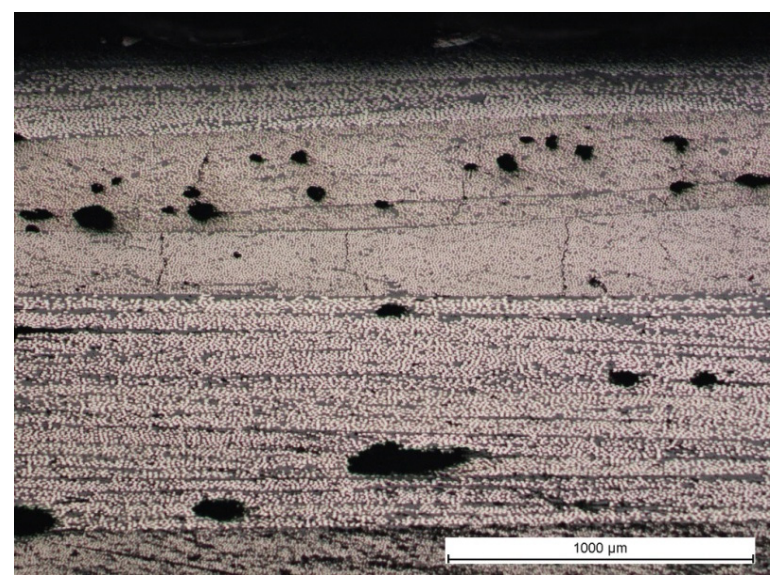

FIGURE 23. Laminate view in tangential direction of the test section 
The CHATT results are well in line with the NASA results regarding cryogenic tank development. The use of a fully load carrying liner (TeXtreme $\left.{ }^{\circledR}\right)$ compliant with the rest of the laminate, three integrated liners, higher strain allowable and out-of-autoclave manufacture, enabled a predicted $30 \%$ structural weight reduction. The introduction of thin-ply materials may thus enable new space vehicle designs.

\subsection{Thin-Ply Sample Calculations}

For structural applications within the Aurora study, the material strength increase potential of thin-plies is of primary interest. This shall be addressed in this section with an illustrative example.

Tsai and $\mathrm{Wu}$ [13] presented a general quadratic function form of failure criterion, which in the special case of plane stress for a transversely isotropic material such as a UD ply, is given according to:

$$
\begin{gathered}
F_{1} \sigma_{11}+F_{2} \sigma_{22}+F_{11} \sigma_{11}^{2}+F_{22} \sigma_{22}^{2} \\
+2 F_{12} \sigma_{11} \sigma_{22}+F_{66} \sigma_{12}^{2}=1
\end{gathered}
$$

With strength coefficients according to [14]:

$$
\begin{gathered}
F_{1}=\frac{1}{X_{t}}-\frac{1}{X_{c}}, F_{2}=\frac{1}{Y_{t}}-\frac{1}{Y_{c}}, \\
F_{11}=\frac{1}{X_{t} X_{c}}, F_{22}=\frac{1}{Y_{t} Y_{c}}, \\
F_{12}=\frac{-1}{2 \sqrt{X_{t} X_{c} Y_{t} Y_{c}}}, F_{66}=\frac{1}{S^{2}}
\end{gathered}
$$

In Eq. (2) $X$ and $Y$ are the in-plane strength in fibre and transverse direction respectively, and $S$ is the shear strength of an unconstrained UD material. Subscripts are $t=$ tension and $c=$ compression. The Tsai-Wu criterion is an interactive failure criterion which due to its closed and bound single expression form may be conveniently implemented to predict first-ply failure. The criterion will be used here in 2 simple load cases as an example showing how a decreased ply thickness can allow for higher first-ply failure design limits. The material is a

\begin{tabular}{|c|c|c|c|c|c|}
\hline$E_{1}(\mathrm{GPa})$ & \multicolumn{2}{|c|}{$E_{2}(\mathrm{GPa})$} & \multicolumn{2}{|c|}{$G_{12}(\mathrm{GPa})$} & $v(-)$ \\
\hline 150 & \multicolumn{2}{|l|}{9} & \multicolumn{2}{|c|}{6} & 0.3 \\
\hline $\begin{array}{c}X_{t} \\
(\mathrm{MPa})\end{array}$ & $\begin{array}{c}X_{c} \\
(\mathrm{MPa})\end{array}$ & & $\begin{array}{l}Y_{t} \\
\mathrm{~Pa})\end{array}$ & $\begin{array}{c}Y_{c} \\
(\mathrm{MPa})\end{array}$ & $\begin{array}{c}S \\
(\mathrm{MPa})\end{array}$ \\
\hline 2250 & 1300 & & 5 & 200 & 70 \\
\hline
\end{tabular}
HTS carbon fibre reinforced epoxy composite with mechanical properties as shown in TABLE 7, whereas $E$ is the elastic modulus, $G$ the shear modulus, and $v$ the Poisson ratio.
TABLE 7. Mechanical properties of an HTS CF/EP UD composite

The laminate is quasi-isotropic with a $[45,90,-45,0] \mathrm{s}$ stacking sequence with plies of thickness $t_{\text {ply }}$ of $0.15 \mathrm{~mm}$ (i.e. pre-preg type) or $0.05 \mathrm{~mm}$ (thin plies). For the purpose of this analysis we need to calculate the in-situ properties for both thicknesses and also apply the residual stresses from manufacturing, calculated assuming a temperature change $\Delta T=-157^{\circ} \mathrm{C}$ from the curing temperature to room temperature. $\alpha_{1}=0.5 \cdot 10^{-6}$ and $\alpha_{2}=30 \cdot 10^{-6} 1 /{ }^{\circ} \mathrm{C}$ are the assumed thermal expansion coefficients of the UD plies. The so called in-situ effect in laminated composites has been studied quite extensively over the years. The case of a ply embedded between two constraining plies was considered theoretically and experimentally by Dvorak \& Laws [15]. The in-situ strength related to the material and laminate used in this study were calculated by applying the equations for the insitu effects presented by [16] and [17], with the subscript $L$ denominating the longitudinal direction.

$$
\begin{gathered}
Y_{t}^{i s}=\sqrt{4 G_{I C} E_{2} / \pi t^{*}} \\
S_{L}^{i s}=\sqrt{\frac{\left(1+\beta 48 G_{I I C} G_{12}^{2} / \pi t^{*}\right)^{1 / 2}-1}{3 \beta G_{12}}}
\end{gathered}
$$

The shear stress-strain relation was approximated by the equation:

$$
\gamma_{12}=\sigma_{12} / G_{12}+\beta \sigma_{12}^{3}
$$

Where the experimental shear curve was fitted by using the fitting parameter $\beta=2 \cdot 10^{-8} / \mathrm{MPa}^{3}$ for this material. The effective ply thickness is $t^{*}=2 t_{\text {ply }}$ for a surface ply and $t^{*}=t_{p l y}$ for an embedded ply. The mode I fracture toughness, related to tensile stress related crack opening, was determined from Double Cantilever Beam (DCB) specimens, $G_{I C}=165 \mathrm{~J} / \mathrm{m}^{2}$ at crack growth initiation and used in this analysis. The shear stress related mode II fracture toughness was assumed with $G_{I I c}=3.1 G_{I c}=512 \mathrm{~J} / \mathrm{m}^{2}$ using the relation derived in [18]. With these values it was checked that the limit for "thin" vs "thick" embedded ply according to the definition by Pinho et al. [17] was about $0.28 \mathrm{~mm}$ for $S_{L}^{\text {is }}$ and $0.37 \mathrm{~mm}$ for $Y_{t}^{i s}$. Therefore Eq. (3) and (4) were used both for embedded and surface plies. The load cases were either (i) 
uniaxial strain $\varepsilon_{x}$ or (ii) equal biaxial strain $\varepsilon_{x}=\varepsilon_{y}$ including residual stress applied to the laminate. The results when using the calculated in-situ strengths, the Tsai-Wu criterion and classical laminate analysis are shown in TABLE 8.

\begin{tabular}{|c|c|c|}
\hline Load case & $t_{p l y}=0.15 \mathrm{~mm}$ & $t_{p l y}=0.05 \mathrm{~mm}$ \\
\hline$\varepsilon_{x}$ & $0.67 \%$ & $1.20 \%$ \\
\hline$\varepsilon_{x}=\varepsilon_{y}$ & $0.54 \%$ & $1.23 \%$ \\
\hline
\end{tabular}

TABLE 8. First-ply failure strain prediction for two simple load cases

This simplified example shows the potential using thin plies when it comes to allowing for increase in strain design limit (first-ply failure). However, it also highlights another implication of using thin plies: the onset for matrix failure is approaching the strain limit of fibre failure, i.e. the failure limit of the ultimate load bearing plies. The consequence being that there will be only limited damage development prior to failure, leading to a brittle to quasi-brittle behaviour of the laminate.

\subsection{Evaluation of Thin-Ply Application for Aurora}

Based on the structural analysis results discussed in Chapter 3, the effect of ply thickness variation with respect to vehicle structure mass shall be demonstrated for the R1 and R2 configuration. Thereby, the focus is placed on two aspects: minimum thickness/ply-number effects, and material strength increase.

\subsubsection{Aurora-R1}

For thin-ply application studies, an IM7/APC-2 vehicle structure at $T_{\text {skin }}=375 \mathrm{~K}$ structural skin temperature has been selected (see FIGURE 8). This leaves a contingency margin to the maximum allowed temperature of $T_{\text {skin }}=394 \mathrm{~K}$. Vehicle structural analyses have been done with varying ply thicknesses between $t_{p l y}=0.25 \mathrm{~mm}$ and $t_{p l y}=0.025 \mathrm{~mm}$, with the results being shown in FIGURE 24. Note that no material property changes have been considered. Thus, the change in structural mass is solely a result of the more efficient material utilization, most notably minimum ply number effects. The results reveal an impressive structural mass saving potential. The lowest ply thickness of $t_{p l y}=0.025 \mathrm{~mm}$ allows for mass reduction of $38.1 \%$ compared to the highest ply thickness of $t_{\text {ply }}=0.25 \mathrm{~mm}$. Between $t_{\text {ply }}=0.05 \mathrm{~mm}$ and $t_{\text {ply }}=0.025 \mathrm{~mm}$ no significant mass saving can be achieved anymore, implying that in this case $0.05 \mathrm{~mm}$ is a reasonable target value. When compared to the baseline ply thickness of $0.125 \mathrm{~mm}$ as used for the results shown in FIGURE 8 before, $t_{p l y}=0.05 \mathrm{~mm}$ still allows for a mass saving of $13.2 \%$. It is explicitly to be noted that mass savings of this order are to a large extent a result of the generally low thicknesses of the facesheets of the vehicle, that are in many cases sized by minimum ply number considerations rather than mechanical loads. In case of highly loaded structures with high wall thicknesses lower mass savings are to be expected.

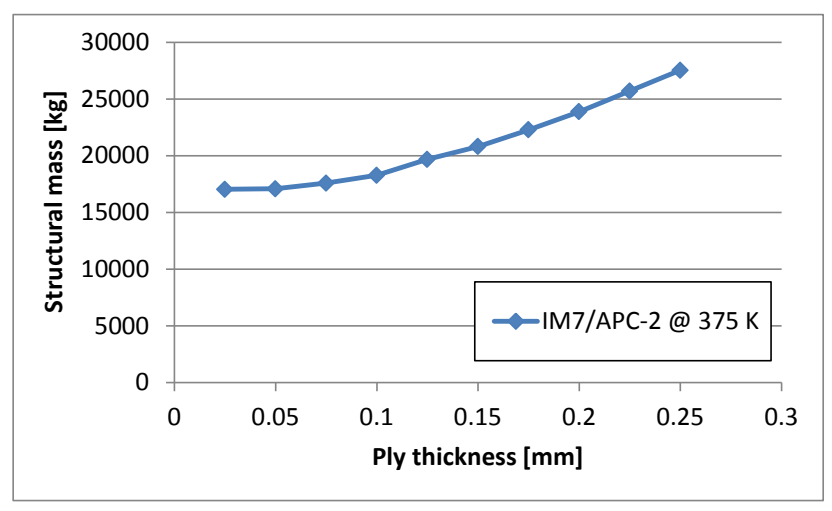

FIGURE 24. Computed structural masses for different ply thicknesses

FIGURE 25 further investigates the effect of the reduction of ply thickness. Shown here is the fraction of vehicle facesheets that are sized according to different sizing criteria. As can be seen, in case of $t_{p l y}=0.25 \mathrm{~mm}$ the majority of the facesheets are sized according to minimum ply number / minimum thickness considerations. If the ply thickness is reduced, the number of components sized by actual strength and stability criteria increases. Note that no discrimination between minimum thickness and minimum ply number is made in FIGURE 25. Especially for the thin ply example $\left(t_{p l y}=0.025 \mathrm{~mm}\right)$ many facesheets are at the minimum allowed thickness of $0.5 \mathrm{~mm}$ and can therefore not further be reduced in thickness.

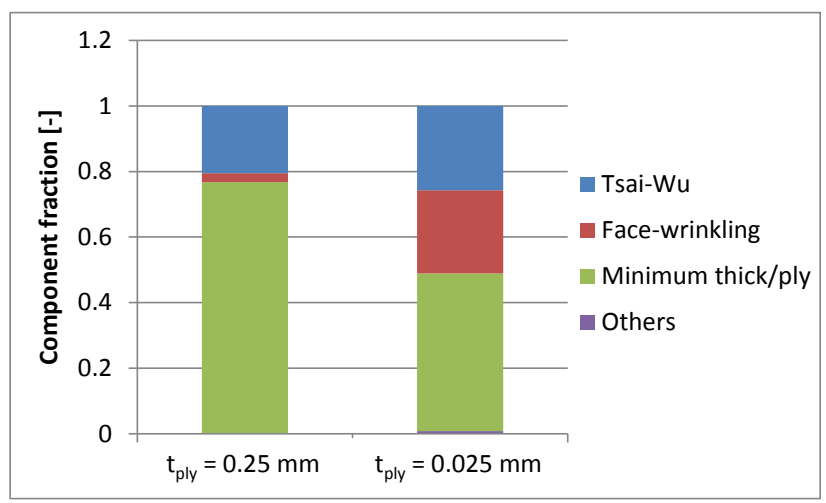

FIGURE 25. Sizing criteria for two selected ply thicknesses

In FIGURE 26 the impact of material strength increases is investigated. The thin ply effect can lead to an increase in the material transverse and shear strength, as discussed before. The generic example calculations shown in Section 4.3 indicate an impressive strength increase potential by a factor of $\approx 2$ when switching from $0.15 \mathrm{~mm}$ to $0.05 \mathrm{~mm}$ ply thickness. However, the calculations have been made using a different material type and generic loading condition, and furthermore compare $t_{p l y}=0.05 \mathrm{~mm}$ with $t_{p l y}=0.15 \mathrm{~mm}$ rather than with $0.125 \mathrm{~mm}$ as appropriate here. Thus, for the analysis shown in FIGURE 26 generic strength increases of 10\% 
to $50 \%$ have been considered. Computations have been done for an IM7/APC-2 vehicle structure at $T_{\text {skin }}=375 \mathrm{~K}$ using $t_{p l y}=0.05 \mathrm{~mm}$. The resulting structural masses illustrate that a structural mass reduction of $6.2 \%$ could be reached when increasing transverse and shear strengths by 50\%. FIGURE 27 shows the fraction of vehicle component facesheets sized according to different sizing criteria. As can be seen, with increasing material strength the number of components sized by strength (Tsai-Wu) reduces, while the number fraction for the other sizing criteria increases.

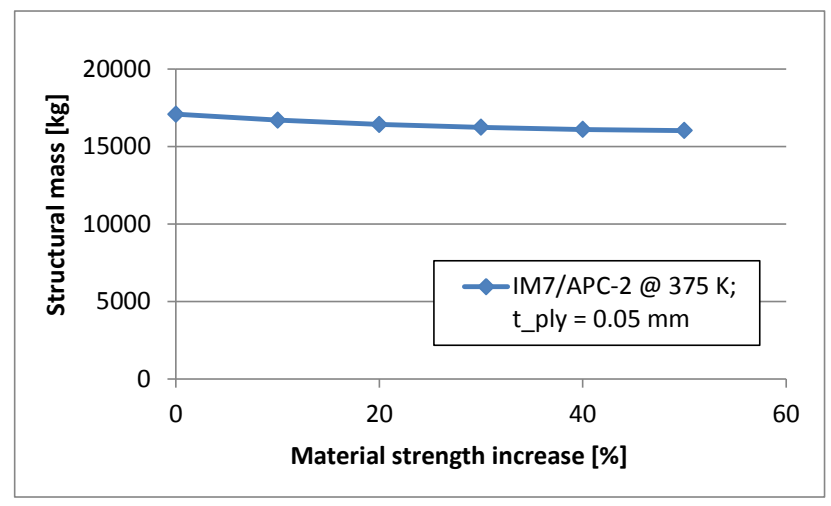

FIGURE 26. Computed structural masses as a function of material transverse and shear strength increase

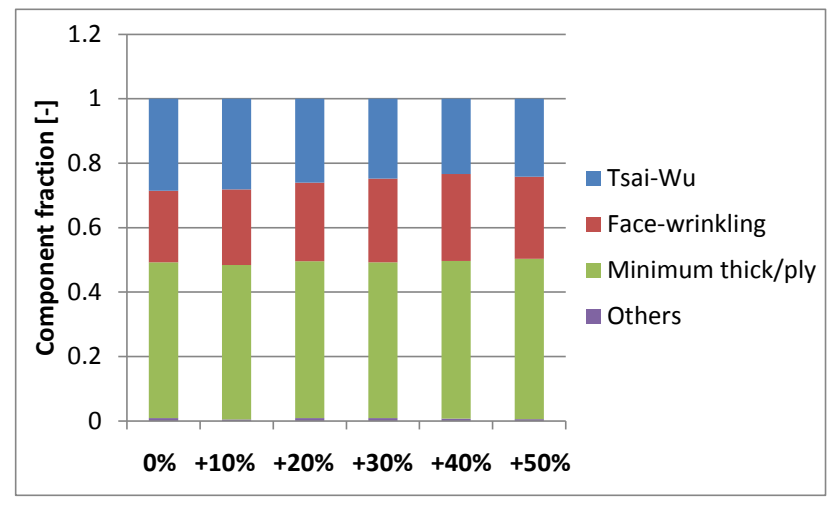

FIGURE 27. Sizing criteria for material strength increase investigation

FIGURE 28 provides a structural component group mass breakdown for the strength increase investigation. The highest structural mass saving of up to $8.2 \%$ could be achieved for the wings skins. The lowest mass benefit was found for the wing ribs, where the maximum weight saving was only $3.2 \%$. Note that the relatively high mass of the frame group is a result of a minimum sandwich core thickness of $50 \mathrm{~mm}$, which was applied only for the frames.

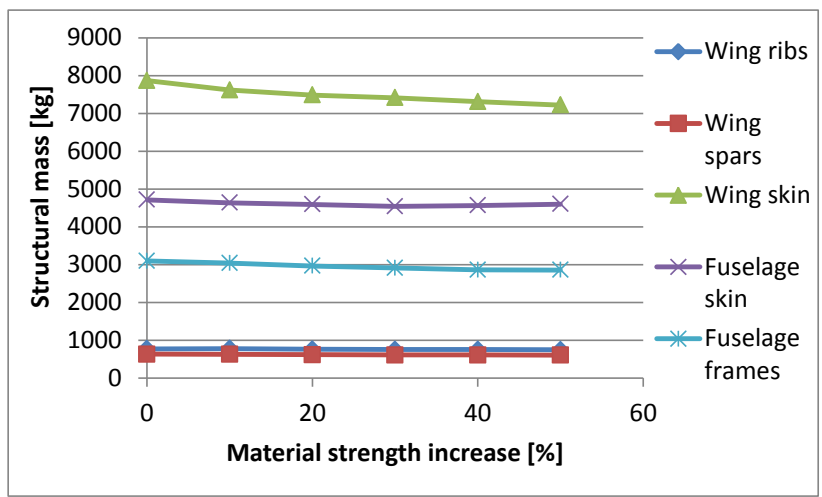

FIGURE 28. Component breakdown for computed structural masses as a function of material transverse and shear strength increase

In summary, the Aurora-R1 airframe study indicated that for an IM7/APC-2 vehicle structure with $375 \mathrm{~K}$ structural skin temperature, a structural mass saving of $18.5 \%$ can be reached when switching from the baseline $0.125 \mathrm{~mm}$ plies to $0.05 \mathrm{~mm}$ plies and assuming a generic, but not unrealistic strength increase of $50 \%$. Compared to a vehicle structure with relatively thick plies of $0.25 \mathrm{~mm}$, the mass saving would even be $41.8 \%$.

\subsubsection{Aurora-R2}

Similar to the R1 configuration, an IM7/APC-2 vehicle structure at $T_{\text {skin }}=375 \mathrm{~K}$ structural skin temperature has been selected for R2. FIGURE 29 presents the effect of ply thickness reduction induced more efficient material utilization. The mass benefit is here even higher than in the case of the R1 configuration. The lowest considered ply thickness of $t_{\text {ply }}=0.05 \mathrm{~mm}$ allows for a structural mass saving of an impressive $49.9 \%$ with respect to highest ply thickness of $t_{p l y}=0.25 \mathrm{~mm}$. When comparing a ply thickness of $0.05 \mathrm{~mm}$ with the baseline ply thickness of $0.125 \mathrm{~mm}$, the mass saving is still $20.3 \%$. It is striking that the structural mass reduction with reduced ply thickness is almost linear down to $t_{p l y}=0.075 \mathrm{~mm}$ - which is in contrast to the R1 analysis results. The reason is that due to the very efficient structural and load path architecture, the stresses in the facesheets are low for most structural components. Thus, most of the facesheets are actually sized by minimum ply-number considerations. Therefore, a decrease in ply thickness by a certain percentage will almost directly translate into a structural mass saving of similar magnitude. Another observation is the striking bend of the mass curve at the lowest ply thicknesses. This is a result of the minimum thickness limit of $0.5 \mathrm{~mm}$ per facesheet.

Similar to the R1 configuration, material strength increase investigations were performed as well. However, even for $0.05 \mathrm{~mm}$ ply thickness only $10 \%$ of the structural members were found to be sized by strength. Therefore, material strength increases did not result in significant mass savings. 


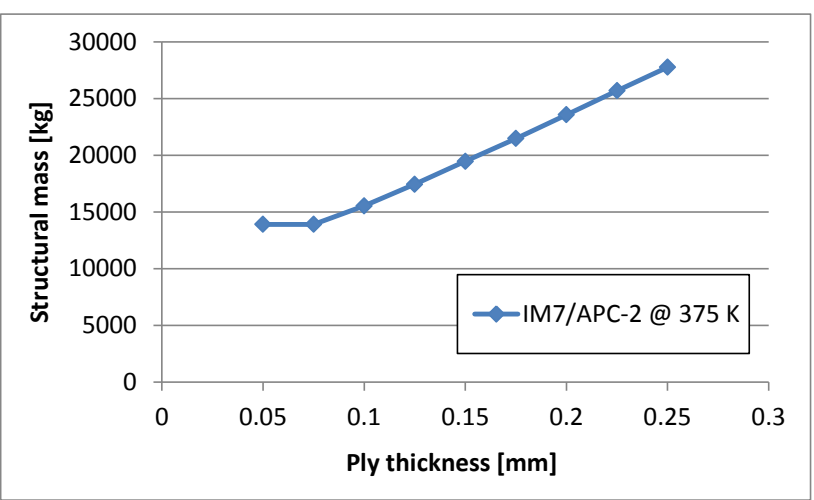

FIGURE 29. Computed structural masses for different ply thicknesses

FIGURE 30 and FIGURE 31 show the computed sandwich facesheet and core thicknesses for a design with $t_{p l y}=0.05 \mathrm{~mm}$. Most facesheets are at or close to the $0.5 \mathrm{~mm}$ minimum thickness boundary. The maximum facesheet thickness is $3.3 \mathrm{~mm}$, and is found in the main engine thrust introduction area. The sandwich core heights reach values of up to $50 \mathrm{~mm}$ at the vehicle center line, which corresponds to the maximum allowed core height.

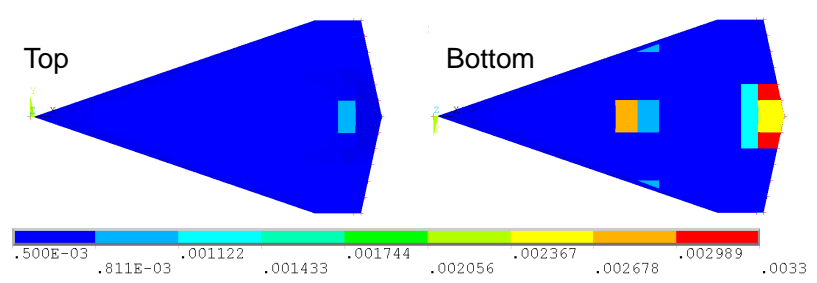

FIGURE 30. Computed sandwich facesheet thicknesses in [m] (single facesheet)

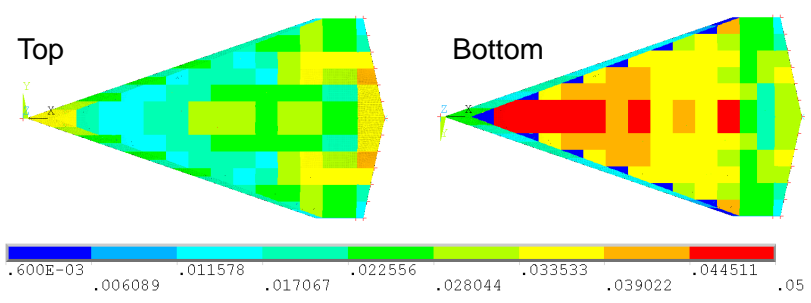

FIGURE 31. Computed sandwich core heights in [m]

\subsubsection{Concluding Discussion of Thin-Ply Application Perspectives}

The thin-ply application results, although of preliminary nature, indicate significant mass saving potentials on vehicle level. The focus was so far on minimum thickness/ply-number effects and material strength increase. When considering these two effects, it can be concluded that thin-ply composite utilization is in particular interesting if:

- thin skins/facesheets are present, as then minimum thickness/ply-number criteria can be determining for the panel mass;

- therefore sandwich panels will in tendency achieve higher mass savings than for instance stringer-stiffened structures;

- the structural design is strength rather than stiffness driven, as thin-plies can improve material strength but not the elastic modulus.

As indicated in Section 4.1-4.2, other effects that have not yet been investigated here might result in further mass savings. This might include:

- $\quad$ structural designs with temperature cycling effects, as thin-plies delay or even eliminate the temperature-induced creation of micro-cracks;

- this is of high interest for cryogenic propellant tanks, as well as for the increase of operation temperatures for airframes subjected to elevated temperatures;

- designs which include sophisticated stacking optimization procedures, as thin-plies give the designer more degrees of freedom for a given laminate thickness.

Thin-ply composites are already in use for various applications, including light aircraft primary structures. Principal drawbacks include the increased manufacturing costs . For a given laminate thickness more plies have to be placed, and higher manufacturing quality is required to fully exploit the advantages of thin-plies. This has to be traded against the mass saving potential. Space launchers are particularly interesting for thin-ply application due to their inherent very high mass sensitivity compared to other aerospace vehicles.

\section{SUMMARY AND CONCLUSION}

This paper introduced the Aurora space launcher system design study and its background. The current design status and/or the design perspectives for three vehicle configurations have been discussed. Also, a brief overview of the thin-ply CFRP technology was provided, and the application of this technology for two Aurora configurations was discussed in detail.

Although the vehicle system design and structural analysis procedures are simplified, the principal mass saving potential of thin-ply composites could be demonstrated. The investigations indicate that structural mass savings in the order of $\sim 20 \%$ compared to conventional CFRP appear to be realistic. Future investigations will utilize more sophisticated analysis procedures to quantify the actual mass saving potential with a higher accuracy and reliability. Thereby it is important to always consider the vehicle level since theoretical improvements on material level cannot directly be extrapolated to vehicle level weight savings without a representative vehicle design. The actual mass saving potential strongly depends on the particular structural and material concepts, as well as on the vehicle and mission design and the corresponding loading environment. In particular, highly loaded vehicle 
structures operating under high stresses and with comparatively thick skins will not profit from thin-ply induced more efficient material utilization in the same magnitude as Aurora R1 and R2. In such a case however the benefit of increased material strengths might be significantly higher than found here. Further mass savings might be possible for many structures if the structure and material architecture would be optimized for thin-plies.

The structural analyses have furthermore demonstrated that compact configurations with high geometric moments of inertia (high fuselage diameters and/or wing thicknesses) and mass distributions for efficient mass/lift matching are a very promising strategy for enabling extremely lightweight vehicle structures. Air-breathing configurations are here slightly penalized as slender and therefore less compact configurations are required for high aerodynamic performance.

Based on the promising results for the first Aurora study configurations, further Aurora configurations will be defined in a higher level of detail, including pure rocket as well as rocket/air-breathing combined cycle concepts. Thereby, not only thin-ply composites, but also latest technological improvements in areas such as thermal protection and propulsion technology will be included. A special focus will be placed on the further development and detailing of the R2 configuration, as this vehicle concept offers a promising combination of reasonable good payload performance, comparatively low development and operation costs, and high operational robustness and operational readiness.

\section{REFERENCES}

[1] Roorda, E.: Configuration and Preliminary Design Studies for the "LEO Fracht Transporter" (LFT) Concept. DLR SART TN-016/2015, Bremen (2016)

[2] Spies, J., Kuczera, H.: The Sub-Orbital Hopper - one of FESTIP's Preferred Concepts. AIAA-99-4945, 9th International Space Planes and Hypersonic Systems and Technologies Conference, Norfolk (1999)

[3] Cook, S.: X-33 Reusable Launch Vehicle Structural Technologies. AIAA-96-4563, AIAA 7th International Space Planes and Hypersonic Systems and Technologies Conference, Norfolk (1996)

[4] Longstaff, R., Bond, A.: The Skylon Project. AIAA2011-2244, 17th International Space Planes and Hypersonic Systems and Technologies Conference, San Franciso (2011)

[5] Blosser, M.L.: Advanced Metallic Thermal Protection Systems for Reusable Launch Vehicles. $\mathrm{PhD}$ thesis, Graduate School of Engineering and Applied Science, University of Virginia (2000)

[6] www.oxeon.se

[7] http://www.compositesworld.com/articles/spreadtow-technology-takes-off-
[8] Vickers, J.: NASA Composite Cryotank Technology Project Game Changing Program. NASA Marshall Space Flight Center (2015)

[9] NASA: Game Changing Development Program, Thin-Ply Composites for Space Exploration Applications - Request for Information. Number NNH15ZOA007L, NASA (2015)

[10] Amacher, R., Cugnoni, J., Botsis, J., Sorensen, L., Smith, W., Dransfeld, C.: Thin ply composites: Experimental characterization and modeling of size effects. Composite Science and Technology 101 (2014) 121-132.

[11] Mattsson, D.: Liner-less tanks for cryogenic applications - Final report. CHATT Deliverable D3.4.7, Swerea SICOMP (2015)

[12] Sippel, M., Kopp, A., Mattsson, D., Freund, J., Tapeinos, I., Koussios, S.: Final Results of Advanced Cryo-Tanks Research Project CHATT. 6th European Conference for Aeronautics and Space Sciences EUCASS (2015)

[13] Tsai S. W., Wu E. M.: A general theory of strength for anisotropic materials. Journal of Composite Materials (1971), 5:58-80

[14] Liu K. S., Tsai S. W.: A progressive quadratic failure criterion for a laminate. Composites Science and Technology (1998), 58:1023-1032

[15] Dvorak G. J., Laws N.: Analysis of progressive cracking in composite laminates II. First ply failure. Journal of Composite Materials (1987), 21:309-329

[16] Camanho P. P., Dávila C. G., Pinho S. T., Iannucci L., Robinson P.: Prediction of in situ strengths and matrix cracking in composites under transverse tension and in-plane shear. Composites Part A (2006), 37:165-176

[17] Pinho S. T., Darvizeh R., Robinson P., Schuecker C., Camanho P.P.: Material and structural response of polymer-matrix fibre-reinforced composites. Journal of Composite Materials (2012), 46:2313-2341

[18] Xia Z. F., Hutchinson J. W.: Mode II fracture toughness of a brittle adhesive layer. International Journal of Solids and Structures (1994), 31:11331148

[19] Shanley, F. R.: Weight-Strength Analysis of Aircraft Structures. Second Edition, Dover Publications Inc., New York (1960)

[20] Bardenhagen, A.: Massenabschätzung und Gesamtauslegung der Unterstufe von HyperschallRaumtransportern. PhD thesis, Institute of Aircraft Design and Lightweight Structures, Technical University of Braunschweig (1998)

[21] Garbers, N.: Overall Preliminary Design of the Thermal Protection System for a long Range Hypersonic Rocket-Powered Passenger Vehicle (SpaceLiner). 7th European Workshop on Thermal Protection Systems and Hot Structures. Noordwijk (2013)

[22] Jenkins, D. R.: Space Shuttle - The History of the National Space Transportation System - The First 
100 Missions. Sixth Printing, Crecy Publishing Ltd, Manchester (2010)

[23] Johnson, T. F., Gates, T. S.: High Temperature Polyimide Materials in Extreme Temperature Environments. AIAA-2001-1214, 42nd AIAA/ASME/ASCE/AHS/ASC Structures, Structural Dynamics, and Materials Conference and Exhibit, Seattle (2001)

[24] APC-2 PEEK Thermoplastic Polymer. Cytec technical data sheet

[25] Dumbacher, D. L.: X-37 Flight Demonstrator Project: Capabilities for Future Space Transportation System Development. IAC-04-V-6.05, 55th International Astronautical Congress, Vancouver (2004)

[26] Jenkins, D. R., Landis, T. R.: Valkyrie - North American's Mach 3 Superbomber. Specialitypress, North Branch (2004)

[27] Koch, A.: META CE Workshop: Technical Note. DLR Bremen (2014)

[28] Candel, S.: Concorde and the Future of Supersonic Transport. Journal of Propulsion and Power, Vol. 20, No. 1 (2004) 